NBER WORKING PAPER SERIES

\title{
DO CONSUMERS RESPOND TO MARGINAL OR AVERAGE PRICE? EVIDENCE FROM NONLINEAR ELECTRICITY PRICING
}

\author{
Koichiro Ito \\ Working Paper 18533 \\ http://www.nber.org/papers/w18533 \\ NATIONAL BUREAU OF ECONOMIC RESEARCH \\ 1050 Massachusetts Avenue \\ Cambridge, MA 02138 \\ November 2012
}

I thank Michael Anderson, Maximilian Auffhammer, Peter Berck, Severin Borenstein, James Bushnell, Howard Chong, Pascal Courty, Lucas Davis, Ahmad Faruqui, Meredith Fowlie, Michael Greenstone, Michael Hanemann, Catie Hausman, David Molitor, Erica Myers, Hideyuki Nakagawa, Karen Notsund, Paulina Oliva, Carla Peterman, Emmanuel Saez, James Sallee, Sofia Berto Villas-Boas, and Catherine Wolfram for helpful conversations and suggestions. I also thank seminar participants at Boston University, Cornell, International IO Conference, NBER, POWER Research Conference, Stanford, University of Arizona, University of Calgary, UC Berkeley, UC Davis, UC Irvine, UC San Diego, University of Chicago, University of Illinois Urbana Champaign, University of Maryland, University of Michigan, University of Toronto for helpful comments. I thank the California Public Utility Commission, San Diego Gas \& Electric, and Southern California Edison for providing residential electricity data for this study. Financial support from the California Energy Commission, Resources for the Future, the University of California Energy Institute is gratefully acknowledged. The views expressed herein are those of the author and do not necessarily reflect the views of the National Bureau of Economic Research.

NBER working papers are circulated for discussion and comment purposes. They have not been peerreviewed or been subject to the review by the NBER Board of Directors that accompanies official NBER publications.

(C) 2012 by Koichiro Ito. All rights reserved. Short sections of text, not to exceed two paragraphs, may be quoted without explicit permission provided that full credit, including $\odot$ notice, is given to the source. 
Do Consumers Respond to Marginal or Average Price? Evidence from Nonlinear Electricity Pricing

Koichiro Ito

NBER Working Paper No. 18533

November 2012

JEL No. L11,L51,L94,L98,Q41,Q48,Q58

\begin{abstract}
Nonlinear pricing and taxation complicate economic decisions by creating multiple marginal prices for the same good. This paper provides a framework to uncover consumers' perceived price of nonlinear price schedules. I exploit price variation at spatial discontinuities in electricity service areas, where households in the same city experience substantially different nonlinear pricing. Using household-level panel data from administrative records, I find strong evidence that consumers respond to average price rather than marginal or expected marginal price. This sub-optimizing behavior makes nonlinear pricing unsuccessful in achieving its policy goal of energy conservation and critically changes the welfare implications of nonlinear pricing.
\end{abstract}

Koichiro Ito

Stanford Institute for Economic Policy Research

Stanford University

366 Galvez Street

Stanford, CA 94305-6015

koichiro.ito@stanford.edu 


\section{Introduction}

A central assumption in economics is that firms and consumers optimize with marginal price. For example, consider taxpayers faced with a nonlinear income tax schedule. The theory of optimal taxation assumes that taxpayers respond to their marginal tax rate by making a right connection between their income and nonlinear tax system (Mirrlees 1971, Atkinson and Stiglitz 1976, and Diamond 1998). Likewise, empirical studies in economics generally take this assumption as given when estimating key parameters in a variety of markets that involve nonlinear price, subsidy, and tax schedules. ${ }^{1}$

However, evidence from many recent studies suggests that consumers may not respond to nonlinear pricing as the standard theory predicts. Many surveys find that few people understand the marginal rate of nonlinear price, subsidy, and tax schedules. ${ }^{2}$ Subjects in laboratory experiments show cognitive difficulty in understanding nonlinear price systems and respond to average price. ${ }^{3}$ While the response to nonlinear pricing affects welfare implications of many economic policies, there is no clear evidence on the question: To what price of nonlinear price schedules do consumers respond?

In this paper, I provide a framework to uncover consumers' perceived price of nonlinear price schedules. Economic theory provides at least three possibilities about the perceived price. The standard model of nonlinear budget sets predicts that consumers respond to marginal price. However, in the presence of uncertainty about consumption, rational consumers respond to expected marginal price (Saez 1999; Borenstein 2009). Alternatively,

\footnotetext{
${ }^{1}$ For example, the market for cellular phone (Huang 2008), energy (Reiss and White 2005), labor (Hausman 1985), and water (Olmstead, Michael Hanemann, and Stavins 2007).

${ }^{2}$ See Liebman (1998) and Fujii and Hawley (1988) on tax rates, Brown, Hoffman, and Baxter (1975) on electricity price, and Carter and Milon (2005) on water price.

${ }^{3}$ For example, see de Bartolome (1995) for evidence from laboratory experiments.
} 
consumers may use average price as an approximation of marginal price if the cognitive cost of understanding complex pricing is substantial. This sub-optimization is described as "schmeduling" by Liebman and Zeckhauser (2004).

My analysis exploits price variation at spatial discontinuities in California electricity service areas. Because the territory border of two power companies lies within city limits, households in the same city experience significantly different nonlinear pricing. This research design addresses the long-discussed identification problems in the literature (Heckman 1996; Blundell, Duncan, and Meghir 1998; Goolsbee 2000; Saez, Slemrod, and Giertz 2012) by having nearly identical groups of households experiencing different price variation.

The access to the full administrative data on electricity billing records allow me to construct household-level monthly panel data for essentially all households in the study area from 1999 to 2007. The sample period provides substantial cross-sectional and time-series price variation because the two companies changed their price multiple times independently. The billing data include customers' nine-digit zip code, with which I match census data to show that demographic and housing characteristics are balanced across the territory border of the two power companies.

Results from my three empirical strategies provide strong evidence that consumers respond to average price rather than marginal or expected marginal price. First, I examine whether there is bunching of consumers at the kink points of nonlinear price schedules. Such bunching must be observed if consumers respond to marginal price (Heckman 1983; Saez 2010; Chetty et al. 2011). I find no bunching anywhere in the consumption distribution despite the fact that the marginal price discontinuously increases by more than $80 \%$ at some kink points. The absence of bunching implies either that 1) consumers respond to marginal 
price with zero elasticity or 2) they respond to alternative price. To explore this point, I use the encompassing test (Davidson and MacKinnon 1993) to examine whether consumers respond to marginal, expected marginal, or average price. I find that average price has a significant effect on consumption, while the effects of marginal price and expected marginal price become statistically insignificant from zero once I control for the effect of average price in the regression. Finally, I propose a strategy that estimates the shape of the perceived price directly. My model nests a wide range of potential perceived price by allowing consumers to have different weights on each part of their nonlinear price schedule. I empirically estimate the weights, from which I recover the shape of their perceived price. I find that the shape of the resulting perceived price is nearly identical to the shape of average price.

This sub-optimizing behavior changes the policy implications of nonlinear pricing. First, I show that the sub-optimal response makes nonlinear pricing unsuccessful in achieving its policy goal of energy conservation. Many electric, natural gas, and water utilities in the US adopted nonlinear pricing similar to California's residential electricity pricing. ${ }^{4}$ Policy makers often claim that higher marginal prices for excessive consumption can create an incentive for conservation. Contrary to the policy objective, I show that nonlinear tariffs may result in a slight increase in aggregate consumption compared with an alternative flat marginal rate if consumers respond to average price. Second, the sub-optimal response changes the efficiency cost of nonlinear pricing. I show that it reduces the efficiency cost given a reasonable range of assumptions on the private marginal cost of electricity. However, it increases the efficiency cost when the social marginal cost of electricity is substantially high because of negative environmental externalities from electricity generation.

\footnotetext{
${ }^{4}$ BC Hydro (2008) conducts a survey of 61 U.S. utilities and finds that about one-third of them use increasing block pricing for residential customers.
} 
The findings also have important implications for US climate change legislation. In the cap-and-trade program proposed in the American Clean Energy and Security Act of 2009, about $30 \%$ of emission permits would be given to electric utilities for free. The proposal explicitly prohibits distributing the value of the free allowance based on each customer's electricity consumption. Instead, it recommends providing a fixed credit on electricity bills. The rationale behind the policy is to preserve the marginal incentive to conserve electricity. However, if customers respond to average price, the fixed credit to electricity bills still discourages conservation and increases electricity consumption, suggesting that the compensation scheme may need to be reconsidered. ${ }^{5}$

Although the possibility of this sub-optimizing behavior has been long discussed in public finance, industrial organization, and environmental economics, previous studies provide inconclusive results because of several empirical challenges. ${ }^{6}$ First, the access to extensive individual-level data is necessary to examine the question but rarely available to researchers. ${ }^{7}$ Second, Heckman (1996) note that usual non-experimental data do not provide a clean control group because all comparable individuals usually face exactly the same nonlinear price schedule. Third, many studies do not have sufficient exogenous price variation to statistically distinguish the effects of alternative forms of price. My analysis addresses the challenges by exploiting substantial cross-sectional and time-series price variation at the spatial discontinuity of electricity service areas and provides robust empirical findings.

\footnotetext{
${ }^{5}$ Use of allowances is described on page 901 of Congress (2009). Burtraw (2009) and Burtraw, Walls, and Blonz (2010) note that distributing a fixed credit may not work in the desired way if residential customers do not pay attention to the difference between their marginal price of electricity and their electricity bill.

${ }^{6}$ For example, see Shin (1985); Nieswiadomy and Molina (1991); Liebman and Zeckhauser (2004); Feldman and Katuscak (2006); Borenstein (2009).

${ }^{7}$ For example, the price and consumption data used in Shin (1985) are annual data aggregated by the utility company level. Without having individual-level monthly data, it is not possible to identify each consumer's actual marginal and average price.
} 
My findings are consistent with those in the literature that studies consumer inattention to complex pricing. ${ }^{8}$ While many studies test the hypothesis that consumers misperceive complex prices, the actual shape of perceived price is not explicitly examined and remains unknown in most studies. My empirical strategy provides a way to nest a wide range of potential shapes of perceived price, from which researchers can estimate the true shape of perceived price by examining consumer behavior in response to price variation.

\section{Theoretical Predictions}

Economic theory provides three different predictions about consumers' perceived price of nonlinear price schedules. To characterize the predictions, consider a price schedule $p(x)$ in Figure 1. The marginal price of $x$ equals $p_{1}$ for $x \leq k$ and $p_{2}$ for $x>k$. This form of nonlinear pricing is widely used in many economic policies. For example, $p(x)$ can be seen as an income tax schedule of annual income $x$ (Moffitt 1990), an insurance price schedule of utilization $x$ (Aron-Dine et al. 2012), or a price schedule of monthly usage $x$ of cell phone, electricity, or water.

The standard model of nonlinear budget sets predicts that consumers optimize $x$ based on the true marginal price schedule $p(x)$. That is, the perceived price is identical to $p(x)$. This response requires two implicit assumptions: 1) consumers have no uncertainty about $x$ and 2) they fully understand the structure of the nonlinear price schedule. Saez (1999) and Borenstein (2009) relax the first assumption. In their uncertainty model, consumers take into account of their uncertainty about $x$ and respond to their expected marginal price. Aron-Dine

\footnotetext{
${ }^{8}$ See DellaVigna (2009) for a comprehensive survey. Examples include Busse, Silva-Risso, and Zettelmeyer (2006); Gabaix and Laibson (2006); Hossain and Morgan (2006); Chetty, Looney, and Kroft (2009); Finkelstein (2009); Brown, Hossain, and Morgan (2010); Gabaix (2011); Malmendier and Lee (2011); Chetty (2012).
} 
et al. (2012) describe similar forward-looking behavior in a dynamic model. Finally, Liebman and Zeckhauser (2004) relax the second assumption by allowing inattention to complex price schedules. In the inattention model, consumers respond to the average price of their total payment as an approximation of marginal price if the cognitive cost of understanding complex pricing is substantial. In practice, the information required to calculate average price is substantially less than marginal price. Total payment and quantity are sufficient information and the knowledge of the nonlinearity of the price schedule is not necessary.

I consider a general form of perceived price that encompasses all of the three theoretical predictions. Suppose that consumers care about $p(x+\epsilon)$ for a range of $\epsilon$ because they consider uncertainty about $x$ or they have inattention to the price schedule. They construct the perceived price $\tilde{p}(x)$ by deciding relative weights $w(\epsilon)$ on $p(x+\epsilon)$ :

$$
\tilde{p}(x)=\int p(x+\epsilon) w(\epsilon) d \epsilon,
$$

where $\int w(\epsilon) d \epsilon=1$. Panel $\mathrm{B}$ of Figure 1 shows the density functions $w(\epsilon)$ that convert $\tilde{p}(x)$ to marginal, expected marginal, and average prices. In the standard model, consumers care about the price only at $x$. It implies that $w(\epsilon)=1$ for $\epsilon=0$ and thus $\tilde{p}(x)=p(x)$. In the uncertainty model, risk-neutral consumers replace $w(\epsilon)$ by the density function of their uncertainty about $x$. The resulting $\tilde{p}(x)$ is their expected marginal price. In the inattention model, consumers replace $w(\epsilon)$ by the uniform distribution $\mathcal{U}[0, x]$.

Empirically, there are two ways to uncover $\tilde{p}(x)$. The first approach is to assume a certain shape of $w(x)$ based on economic theory and test if it is consistent with data. The second approach is to directly estimate $w(\epsilon)$ to find $\tilde{p}(x)$. I use both approaches. Regardless of 
which approach I use, there are two empirical challenges to identify $\tilde{p}(x)$. First, it requires sufficient exogenous price variation to distinguish competing predictions about the shape of $\tilde{p}(x)$. Second, it requires a well-identified control group to distinguish the effect of price from other factors that also affect consumption. The next section describes how I address the two challenges by exploiting spatial discontinuities in California electricity service areas.

\section{$3 \quad$ Research Design and Data}

This section describes two key features of my research design. First, households in the same city experience different nonlinear pricing because the territory border of two power companies lies within the city limits. Second, they experience substantially different price variation because the power companies change the price schedules independently.

\subsection{A Spatial Discontinuity in Electricity Service Areas}

Southern California Edison (SCE) provides electricity for large part of southern California, and San Diego Gas \& Electric (SDG\&E) provides electricity for most of San Diego County and the southern part of Orange County (Figure A.1). California households are generally not allowed to choose their retail electricity provider; it is determined by the address of their residence. My study focuses on the territory border of SCE and SDG\&E in Orange County because this is the only border in populated areas that also does not correspond to city or county boundaries.

Figure 2 shows the territory border in Orange County. Households in the same city are served by different power companies because the border lies within city limits in six cities. 
This border contrasts with typical territory borders of utility companies, which correspond to city, county, or state boundaries. Why is the border in the city limits? In the 1940's, SCE and SDG\&E connected their transmission lines in this area and established the territory border (Crawford 1991; Myers 1983). The border does not correspond to the city limits because the city limits in this area were established around the 1980's.

Lee and Lemieux (2010) note that geographical discontinuity designs (Black, 1999) should be used with careful investigation of potential sorting and omitted variables at the border. My research design is unlikely to be confounded by such factors for several reasons. First, time-invariant unobservable factors do not affect my results because I use panel data with household fixed effects. Second, households in this area are not allowed to choose their electricity provider. The only way to choose one provider or another is to live in its service area. It is nearly impossible for households to sort based on their expected electricity bill because the relative electricity price between SCE and SDG\&E changes frequently; the price is higher in SCE in some years while it is higher in SDG\&E in other years as presented in the next section. Third, the next section shows that demographic and housing characteristics are balanced across the territory border, suggesting that the systematic sorting is unlikely to have occurred. Finally, it would be a concern if households receive natural gas, a substitute for electricity, from different providers. This is not the case in this area because all households are served by the same natural gas provider, Southern California Gas Company.

\subsection{Nonlinear Electricity Pricing and Price Variation}

Figure 3 shows the standard residential tariff for SCE and SDG\&E in 2002. The marginal price is a step function of monthly consumption relative to a "baseline" consumption level. 
The baseline differs by climate regions in the utility territories. However, because households in this study are in the same climate regions, the baseline is essentially the same for everyone. The baseline is about $10 \mathrm{kWh} /$ day with a slight difference between summer and winter billing months. $^{9}$

Figure 4 shows that the cross-sectional price variation between SCE and SDG\&E also changes over time quite substantially. Until the summer of 2000, SCE and SDG\&E had nearly the same two-tier nonlinear price schedules. The first price shock occurred during the California electricity crisis in the summer of $2000 .{ }^{10}$ The rates for SDG\&E customers started to increase in May in response to increases in wholesale electricity prices. In August, the first and second tier rates increased to $22 \phi$ and $25 \phi$ per $\mathrm{kWh}$. This increase translated into a $100 \%$ rate increase for SDG\&E customers relative to their rates in 1999. In contrast, the rates for SCE customers stayed at 1999 levels because their retail prices were protected from changes in wholesale price during this period. The second price shock happened in 2001, when SCE introduced a five-tier price schedule in June and SDG\&E followed four months later, although their rates were different. Afterwards, they changed the five-tier rates differently over time.

How are the rates determined and why are they different between SCE and SDG\&E? Retail electricity price in California is regulated by the California Public Utility Commission. When regulated utilities change their rates, they need to provide evidence of changes in cost

\footnotetext{
${ }^{9}$ In summer billing months, both SCE and SDG\&E customers in this area receive $10.2 \mathrm{kWh}$ per day for their baseline. In winter billing months, the baseline is $10.1 \mathrm{kWh}$ per day for SCE customers and $10.8 \mathrm{kWh}$ per day for SDG\&E customers. In the billing data, the monthly bills and price variables are calculated based on the exact baseline of each individual bill.

${ }^{10}$ By August of 2000, wholesale electricity prices had more than tripled from the end of 1999, which caused large-scale blackouts, price spikes in retail electricity rates, financial losses to electric utilities in California. Many cost factors and demand shocks contributed to this rise, but several studies have also found the market power of suppliers to be significant throughout this period. See Joskow (2001), Borenstein, Bushnell, and Wolak (2002), Bushnell and Mansur (2005), Puller (2007), and Reiss and White (2008) for more details.
} 
to receive an approval. SCE and SDG\&E have different rates because they have different sources of electricity generation. Changes in input costs thus affect their total costs differently. They also have different cost structures for distributing electricity because they cover quite different service areas in California (Figure A.1). Finally, they had different sunk losses from the 2000-2001 California electricity crisis, required to be collected from ratepayers.

The price variation provides two advantages compared with previous studies. First, the magnitude of the variation is substantial. Cross-sectionally, households have significantly different nonlinear pricing and the variation changes over time substantially. Second, the difference in marginal price between SCE and SDG\&E is often significantly different from the difference in average price between SCE and SDG\&E. For example, consider consumers in the fourth tier in Figure 3. While the marginal price is higher for SCE customers, the average price is higher for SDG\&E customers. This price variation is key to distinguish the response to alternative forms of price in my estimation.

\subsection{Data and Summary Statistics}

Under a confidentiality agreement, SCE and SDG\&E provided the household-level billing history of essentially all residential customers from 1999 to 2007. Each monthly record includes a customer's account ID, premise ID, billing start and end date, monthly consumption, monthly bill, tariff type, climate zone, and nine-digit zip code. It does not include a customer's name, address, and demographic information. To obtain demographic information, I match each customer's nine-digit zip code to a census block group in the 2000 U.S. Census. In my sample, the mean number of households in a nine-digit zip code area is 4.9 and that in a census block group is 217.3. The nine-digit zip code thus allows precise neighborhood 
matching with census data.

My empirical analysis uses the samples that satisfy the following criteria. First, I focus on customers that are on the default standard tariff. ${ }^{11}$ Second, I focus on the six cities that have the border of electricity service areas inside the city limits: Laguna Beach, Laguna Niguel, Aliso Viejo, Laguna Hills, Mission Viejo, and Coto de Caza. Third, to be conservative about potential sorting that could have occurred because of the price changes after 2000, my main analysis focuses on the panel data of households that are at the same premise throughout the sample period. ${ }^{12}$ This procedure results in a data set of 38,674 households.

Table 1 provides summary statistics. I show the means and standard errors for SCE customers and SDG\&E customers separately. The last column shows the difference in the means with the standard error of the difference. I cluster standard errors at the census block group level for the census data and at the customer level for the panel data of electricity billing records. Between SCE and SDG\&E customers, the demographic and housing characteristics are balanced. The mean of electricity consumption during the sample period is about 23 $\mathrm{kWh} /$ day for SCE customers and $24 \mathrm{kWh} /$ day for SDG\&E customers. SCE and SDG\&E had nearly identical price schedules until 1999, before the first major price change in the summer of 2000. The last row shows that the mean of log consumption in 1999 is not statistically different between SCE and SDG\&E customers.

\footnotetext{
${ }^{11}$ Over $85 \%$ of households are on the standard tariff. About $15 \%$ of households are on the California Alternative Rate for Energy (CARE) program, a means-tested tariff for low-income households. About 5\% of households have other tariffs such as time-of-use pricing.

${ }^{12}$ I show that using unbalanced panel of all households does not change my results.
} 


\section{Empirical Analysis and Results}

\subsection{Bunching at Kink Points of Price Schedules}

My first empirical strategy is to examine bunching of consumers at the kink points of nonlinear price schedules (Heckman 1983; Saez 2010; Chetty et al. 2011). In Figure 1, suppose that preferences for electricity consumption are convex and smoothly distributed across the kink point $k$. Then, if consumers respond to the true marginal price $p(x)$, a disproportionate share of demand curves intersect with the vertical part of the schedule. I thus expect a disproportionate share of consumers bunching around the kink point in the data. The amount of bunching should be larger when 1) the discrete jump in marginal price at $k$ is large and 2) the price elasticity of demand is large.

Bunching Analysis Results. In 1999, consumers faced an essentially flat marginal rate with a small step between the first and second tier. Therefore, the distribution of consumption in 1999 can provide a baseline case where there is no steep kink point in the price schedule. Panel A of Figure 5 presents a histogram of consumption for SCE customers in 1999. I use monthly consumption data from all 12 months in 1999. The histogram shows that the consumption is smoothly distributed.

After 2001, SCE introduced a five-tier price schedule. With steep steps in the price

schedule, the consumption distribution should be different from the baseline case observed in 1999. Panel B shows a histogram of consumption for SCE customers in 2007, where SCE had the steepest five-tier price schedule. It shows that the shape of the distribution is as smooth as the histogram in 1999, and there is no bunching around the kink points. In particular, there is no bunching even at the second kink, where the marginal price discontinuously 
increases more than $80 \%$. I find no bunching for any year of the data in SCE and SDG\&E.

The absence of bunching implies two possibilities. First, consumers may respond to marginal price with nearly zero elasticity. Saez (2010) and Chetty et al. (2011) provide methods to estimate the price elasticity with respect to marginal price from the bunching analysis. Both of the methods produce estimates of nearly zero price elasticity with tight standard errors when I apply them to my SCE data in $2007 .{ }^{13}$ Second, consumers may respond to alternative price. If consumers respond to any "smoothed" price such as average price, the price has no more kink points. There can be thus no bunching even if consumers have nonzero price elasticity. The next section examines these possibilities by exploiting panel price variation in SCE and SDG\&E.

\subsection{Encompassing Tests of Alternative Prices}

My second empirical strategy is to test whether consumers respond to marginal, expected marginal, or average price by using the encompassing test (Davidson and MacKinnon 1993). Let $x_{i t}$ denote consumer $i$ 's average daily electricity use during billing month $t$. Suppose that they have quasi-linear utility for electricity consumption. ${ }^{14}$ I allow the possibility that they may respond to marginal price or average price by characterizing their demand by $x_{i t}=\lambda_{i} \cdot m p_{i t}^{\beta_{1}} \cdot a p_{i t}^{\beta_{2}}$ with the price elasticity with respect to marginal price $\left(\beta_{1}\right)$ and average price $\left(\beta_{2}\right)$. Define $\triangle \ln x_{i t}=\ln x_{i t}-\ln x_{i t_{0}}$ in which $t_{0}$ is the previous year's same billing month.

\footnotetext{
${ }^{13}$ For example, the point estimate and standard error of the elasticity is -0.001(0.002) when I apply the method in Saez (2010) for the largest kink point of SCE's price schedule in 2007.

${ }^{14}$ Quasilinear utility functions assume no income effect. In the case of residential electricity demand, income effects are likely to be extremely small. In my sample, a median consumer pays $\$ 60$ electricity bill per month. A 30\% change in all of five tiers would produce an income change of $\$ 18$ per month, about $0.2 \%$ of monthly median household income in my sample. In the literature, the income elasticity estimates of residential electricity demand is between 0.1 to 1.0. The income effect of this price change thus would result in a change in consumption between $0.02 \%$ to $0.2 \%$.
} 
This first-difference eliminates household-by-month fixed effects. Consider the estimating equation:

$$
\triangle \ln x_{i t}=\beta_{1} \triangle \ln m p_{i t}+\beta_{2} \triangle \ln a p_{i t}+\gamma_{c t}+\eta_{i t},
$$

with city-by-time fixed effects $\gamma_{c t}$ and error term $\eta_{i t}=\varepsilon_{i t}-\varepsilon_{i t_{0}}$. An encompassing test examines if one model encompasses an alternative model. For example, if consumers respond to marginal price and do not respond to average price, one expects $\hat{\beta}_{2}=0$ because average price should not affect demand conditional on the effect of marginal price.

A common identification problem of nonlinear pricing is that the price variables are functions of consumption and hence correlated with unobserved demand shocks $\eta_{i t}$. To address the endogeneity, previous studies use a policy-induced price change as an instrument: $\triangle \ln m p_{i t}^{P I}=\ln m p_{t}\left(\tilde{x}_{i t}\right)-\ln m p_{t_{0}}\left(\tilde{x}_{i t}\right)$. This instrument, also called a simulated instrument, computes the predicted price change at a consumption level $\tilde{x}_{i t}$. The instrument thus captures the price change induced by the policy change in the nonlinear price schedule for a consumption level $\tilde{x}_{i t}$. To be a valid instrument, $\tilde{x}_{i t}$ has to be uncorrelated with $\eta_{i t}$. Many studies use the base year's consumption $x_{i t_{0}}$ for $\tilde{x}_{i t}$. However, $x_{i t_{0}}$ is likely to be correlated with $\eta_{i t}$ because the mean reversion of consumption creates a negative correlation between $\varepsilon_{i t_{0}}$ and $\eta_{i t}=\varepsilon_{i t}-\varepsilon_{i t_{0}}$. Blomquist and Selin (2010) and Saez, Slemrod, and Giertz (2012) suggest that consumption in a period midway between $t_{0}$ and $t$ can be used to address the mean reversion problem. Because my analysis use monthly consumption data, the middle period and its consumption can be defined by $t_{m}=t-6$ and $x_{i t_{m}}$. Note that the instrument based on $x_{i t_{m}}$ is not systematically affected by the mean reversion problem because $\varepsilon_{i t}$ and $\varepsilon_{i t_{0}}$ do not directly affect $x_{i t_{m}}$. If there is no serial correlation, $\varepsilon_{i t_{m}}$ and $\eta_{i t}=\varepsilon_{i t}-\varepsilon_{i t_{0}}$ are uncorrelated. Moreover, Blomquist and Selin (2010) show that even if there is serial corre- 
lation, $\operatorname{Cov}\left(\varepsilon_{i t_{m}}, \eta_{i t}\right)$ equals zero as long as the serial correlation depends only on the time difference between the error terms. This is because $\varepsilon_{i t_{m}}$ is equally spaced from $\varepsilon_{i t}$ and $\varepsilon_{i t_{0}}$ and thus would be correlated with $\varepsilon_{i t}$ and $\varepsilon_{i t_{0}}$ in the same manner. ${ }^{15}$

Even if the mean reversion problem is addressed, the instrument based on the level of consumption can still be correlated with $\eta_{i t}$ if high and low electricity users have different growth patterns in consumption. For example, if there is an underlying distributional change in electricity consumption over time, I cannot expect a parallel trend between high and low electricity users. This is exactly the same problem long discussed in the literature of nonlinear taxation (Heckman 1996; Blundell, Duncan, and Meghir 1998; Goolsbee 2000; Saez, Slemrod, and Giertz 2012). A usual quasi-experiment essentially compares the change in income between lower and higher income households. Because all comparable households usually face the same nonlinear tax schedule, there is no clean control group that can be used to control for differential underlying growth between lower and higher income households.

To address the problem, I exploit the spatial discontinuity in electricity service areas. Because households in the same city experience different nonlinear pricing, I can use households on the other side of the border as a control group. My identification assumption is that confounding factors such as underlying distributional changes in consumption are not systematically different across the border. Consider the instrumental variable (IV) regression:

$$
\triangle \ln x_{i t}=\beta_{1} \triangle \ln m p_{i t}+\beta_{2} \triangle \ln a p_{i t}+f_{t}\left(x_{i t_{m}}\right)+\gamma_{c t}+\delta_{b t}+u_{i t}
$$

with instruments, $\triangle \ln m p_{i t}^{P I}=\ln m p_{t}\left(x_{i t_{m}}\right)-\ln m p_{t_{0}}\left(x_{i t_{m}}\right)$ and $\triangle \ln a p_{i t}^{P I}=\ln a p_{t}\left(x_{i t_{m}}\right)-$

\footnotetext{
${ }^{15}$ Another option for $\tilde{x}_{i t}$ is household $i$ 's consumption in 1999. If the serial correlation of $\varepsilon_{i t}$ has minimal impacts on the correlation between the error term in 1999 and the error term in $t$, the consumption in 1999 would not be systematically correlated with $\eta_{i t}=\varepsilon_{i t}-\varepsilon_{i t_{0}}$. I find that using this instrument produces virtually the identical results to my main results.
} 
$\ln a p_{t_{0}}\left(x_{i t_{m}}\right)$. The error term $u_{i t}$ is uncorrelated with $x_{i t_{m}}$ as long as $f_{t}\left(x_{i t_{m}}\right)$ sufficiently controls for confounding factors such as underlying distributional changes in consumption. When all consumers face the same price schedule, flexible controls of $x_{i t_{m}}$ absorb all price variation and destroy identification. In contrast, I can include any flexible controls of $x_{i t_{m}}$ because households experience different nonlinear pricing.

There are many ways to define $f_{t}\left(x_{i t_{m}}\right)$. For example, I can include flexible polynomial functions in $x_{i t_{m}}$. To prevent a functional form assumption as much as possible, I take a nonparametric approach. For each percentile of consumption in $t_{m}$, I define grouping dummy variables by $G_{j, t}=1\left\{x_{j, t_{m}}<x_{i t_{m}} \leq x_{j+1, t_{m}}\right\}$, which equal one if $x_{i t_{m}}$ falls between $j$ and $j+1$ percentiles. These dummy variables are percentile-by-time fixed effects and control for underlying changes in consumption for each part of the consumption distribution. Although city-level economic shocks and weather shocks are absorbed by city-by-time fixed effects $\gamma_{c t}$, the weather impact can be slightly different between households with different billing cycles. To control for the effect, I include billing-cycle-by-time fixed effects $\delta_{b t}$.

Encompassing Tests Results: Figure 6 provides a graphical illustration of the encompassing test. To show an example of year-to-year price variation, the figure uses January billing months and households whose $x_{i t_{m}}$ is on the forth tier of the five-tier price schedule. ${ }^{16}$ The squared-dashed line shows the difference-in-differences (DD) in the mean of log marginal price $\left(\ln m p_{i t}\right)$ for SDG\&E customers relative to SCE customers. For each customer, I calculate the change in log marginal price from 1999. Then, I obtain the DD by subtracting SCE's mean from SDG\&E's mean. The DD estimate thus shows how SDG\&E's marginal price evolved from 1999 relative to SCE. I call it the relative change in marginal price. In

\footnotetext{
${ }^{16}$ The mean consumption in the data $(23 \mathrm{kWh} /$ day $)$ is in the fourth tier of the five-tier price schedule.
} 
the same way, I calculate the DD in the means of predicted $\log$ marginal price $\left(\ln m p_{i t}^{P I}\right), \log$ average price $\left(\ln a p_{i t}\right)$, predicated $\log$ average price $\left(\ln a p_{i t}^{P I}\right)$, and $\log$ consumption $\left(\ln x_{i t}\right)$.

Figure 6 provides several important insights before I proceed to regression analysis. First, the predicted prices (the instruments) and the effective prices are strongly correlated, which implies a strong first-stage relationship. Second, the change in consumption from 1999 to 2000 provides a test for the parallel trend assumption between SDG\&E and SCE customers. If the parallel trend assumption holds, I expect no difference in the change in consumption between SDG\&E and SCE from 1999 to 2000 because they have nearly the same price change. The DD in consumption in 2000 verifies that this is in fact the case. Third, the relative change in marginal price and the relative change in average price are substantially different in 2002, 2003, and 2007. SDG\&E's marginal price decreases more than SCE's marginal price, but its average price increases more than SCE's average price. If consumers respond to marginal price, SDG\&E's consumption should increase more than SCE's consumption in these years. However, the figure shows the opposite result: SDG\&E's consumption decreases more than SCE's consumption. Unless the price elasticity is positive, the relative change in consumption is inconsistent with the relative change in marginal price. Rather, it is more consistent with the relative change in average price, although formal econometric estimation is required to discuss its statistical inference.

Now, I run the instrumental variable estimation in equation (3) by using all monthly billing data from January 1999 to December 2007. Table 2 presents the regression results that examine whether consumers respond to marginal or average price. I cluster the standard errors at the household level to correct for serial correlation. First, I include only the marginal price of electricity as a price variable. Column 1 shows that the price elasticity 
with respect to marginal price is -0.040 . This result contradicts the result in the bunching analysis, where I find nearly zero price elasticity with respect to marginal price. However, the encompassing test in column 3 implies that the significant price elasticity in column 1 comes from spurious correlation. Column 3 includes both marginal and average price as price variables. If consumers respond to marginal price as the standard theory predicts, I expect that average price does not affect demand conditional on the effect of marginal price. Column 3 reveals the opposite result. Once average price is included, adding marginal price does not statistically change the effect of average price. Moreover, the effect of marginal price becomes statistically insignificant from zero.

Because households receive electricity bills at the end of monthly billing periods, they may respond to lagged price rather than contemporaneous price. Column 4 to 6 provide the results with one-month lagged price. Using lagged price does not change the main result. Households respond to lagged average price rather than lagged marginal price. The price elasticity with respect to lagged price is larger than the elasticity with respect to contemporaneous price, suggesting the possibility that consumers respond to lagged price more than contemporaneous price. Table 2 investigates this point. Column 1 shows that consumers respond to lagged prices and the effect of contemporaneous price is statistically insignificant from zero once the effects of lagged prices are controlled. Usually, the most policy-relevant price elasticity is the medium-long run elasticity that includes these lagged responses. Column 2 to 4 include the average of one, two, three, and four-month lagged average prices. The estimated elasticity thus shows the percent change in consumption when consumers experience a persistent change in average price for one to four-month period. The medium-long run price elasticity estimates are larger than the short-run elasticity estimate. 
I find that lagged prices with more than four-month lags have negligible effects and the medium-long run elasticity estimates do not change when I include more than four-month lags.

Next, I examine the possibility that consumers respond to expected marginal price. To find the degree of uncertainty that typical consumers face in their monthly consumption, I estimate the variance of $\ln x_{i t}$ conditional on household-by-month fixed effects and one-month lagged log consumption. The median of the root mean squared error is about 0.2 , suggesting that with this information the average consumer can predict his consumption with a standard error of about $20 \%$. Based on this estimate, I calculate expected marginal price by assuming that consumers have errors with a standard deviation of $20 \%$ of their consumption. Table 4 shows evidence that consumers respond to average price rather than expected marginal price. Column 3 shows that once average price is included, adding expected marginal price does not statistically change the effect of average price. Column 4 to 6 show that using lagged price does not change the result.

The results in this section provide evidence that households respond to average price among the three prices predicted by theory. Figure A.2 and Table A.1 in the appendix show that the results are robust for 1) unbalanced panel data that include all households in my sample period, 2) the samples restricted to households within a certain distance from the border, and 3) alternative instruments. The encompassing test is simple and sufficient for testing competing theoretical predictions. However, it cannot completely eliminate other possibilities of the perceived price. For example, the previous analysis assumes that the average consumer can predict his consumption with a standard error of about $20 \%$. If households have more or less information about their expected consumption, their expected 
marginal price can be different from the assumed expected marginal price. To address this point, the next section uses an approach that examines a general form of the perceived price instead of starting with a particular prediction of perceived price.

\subsection{Estimation of the Shape of Perceived Price}

In the previous two sections, I begin with the particular forms of perceived price derived from the theoretical predictions and examine which of the competing forms of the perceived price is the most consistent with the data. I take a different approach in this section. Consider that consumers have consumption $x_{i t}$ and face a nonlinear price schedule $p\left(x_{i t}\right)$. I define a series of surrounding consumption levels around $x_{i t}$ by $x_{k, i t}=(1+k / 100) x_{i t}$. That is, $x_{k, i t}$ is the level of consumption that is $k \%$ away from $x_{i t}$. Let $p_{k, i t}=p\left(x_{k, i t}\right)$ denote the marginal price for $x_{k, i t}$. Consumers may care about the surrounding marginal prices either because of the uncertainty about their ex-post consumption or inattention to the true price schedule.

I consider that consumers construct their perceived price by deciding relative weights $w_{k}$ on $p_{k, i t}$. Suppose that there is price variation in $p_{k, i t}$ over time. Using the price variation, I estimate $w_{k}$ by observing how consumers respond to changes in $p_{k, i t}$. Then, I can use the estimates of $w_{k}$ to recover the shape of consumers' perceived price. Suppose that consumers may care about the surrounding marginal prices up to a range of $100 \%$ from $x_{i t}$. That is, $-100 \leq k \leq 100$. I model that the density function of $w_{k}$ has the following asymmetric 
exponential functional form:

$$
w_{k}(\alpha, \boldsymbol{\theta})= \begin{cases}\alpha \cdot \frac{\exp \left(-k \cdot \theta_{l}\right)}{\sum_{k \leq 0} \exp \left(-k \cdot \theta_{l}\right)} & \text { for } k \leq 0 \\ (1-\alpha) \cdot \frac{\exp \left(k \cdot \theta_{r}\right)}{\sum_{k>0} \exp \left(k \cdot \theta_{r}\right)} & \text { for } k>0 .\end{cases}
$$

This density function can characterize various forms of perceived price. First, parameter $\alpha$ describes the relative weight on $p_{k, i t}$ between the left and right hand side of $x_{i t}$. For example, $\alpha=1$ implies that consumers do not care about the price on the right side of $x_{i t}$ in the price schedule. Second, parameter $\theta_{l}$ and $\theta_{r}$ describe the slopes of the density function. The exponential form is useful because it can capture nonlinear upward and downward slopes with one parameter. The dashed lines in Figure 7 illustrate two examples of the weighting functions. The first example shows the case with $\alpha=0.5$ and $\theta_{l}=\theta_{r}=-0.1$, where consumers care about the price of the left and right of $x_{i t}$ equally but put larger weights on the price close to $x_{i t}$. The second example shows a similar case but consumers care about the price further away from $x_{i t}$. Using the weighing function, I estimate:

$$
\triangle \ln x_{i t}=\beta \sum_{k=-100}^{100} w_{k}(\alpha, \boldsymbol{\theta}) \cdot \triangle \ln p_{k, i t}+f_{t}\left(x_{i t_{m}}\right)+\gamma_{c t}+\delta_{b t}+u_{i t}
$$

This estimation is nonlinear only in parameters and linear in variables. I can thus run nonlinear IV estimation without having additional identifying assumptions than the linear IV estimation in the previous section (Amemiya, 1983). ${ }^{17}$ For the endogenous variable $\triangle \ln p_{k, i t}$,

\footnotetext{
${ }^{17}$ An alternative approach is to use a continuous density function for $w$. It makes the estimating equation nonlinear both in parameters and variables, requiring stronger identifying assumptions for nonlinear IV estimation. Because the marginal price $p_{k, i t}$ is flat in most parts of the five-tier price schedule and does not change with a slight change in $k$, the discrete approximation in equation (5) would not significantly deviate from the continuous form of $w$.
} 
I use the same form of the instrument used in the previous section, $\triangle \ln p_{k, i t}^{P I}=\ln p_{t}\left(x_{k, i t_{m}}\right)-$ $\ln p_{t_{0}}\left(x_{k, i t_{m}}\right)$.

The primary interests are the three weighing parameters, $\alpha, \theta_{l}$, and $\theta_{r}$. If consumers respond to expected marginal price, I expect that $\alpha=0.5$ and $\theta_{l}=\theta_{r}$ regardless of the actual degree of uncertainty in consumption that consumers face. The values of $\theta_{l}$ and $\theta_{r}$ reflect the uncertainty but the density $w_{k}(\alpha, \boldsymbol{\theta})$ should be symmetric. If consumers respond to marginal price, I expect steep slopes in $\theta_{l}$ and $\theta_{r}$. Finally, if consumers respond only to average price, I expect that $\alpha=1$ because they would not care about the price above $x_{i t}$. Elasticity parameter $\beta$ is the overall price elasticity and $\beta \cdot w_{k}(\alpha, \boldsymbol{\theta})$ shows the price elasticity with respect to the change in each of $p_{k, i t}$.

Perceived Price Estimation Results. Table 5 shows the estimation results. Column 1 uses contemporaneous price as a price variable. The estimated $\alpha$ is 0.911 . The last two rows show that I reject $\alpha=0.5$ with $1 \%$ significance level and cannot reject $\alpha=1$. That is, I reject that consumers have equal weights on the left and right side of $x_{i t}$ and the estimated $\alpha$ is not statistically different from 1 . Although the estimates of $\theta_{l}$ and $\theta_{r}$ imply that the slopes are asymmetric, both of them are not statistically different from 0 . The solid line in Figure 7 plots the estimated weighting function. The shape is close to a uniform distribution and it is statistically not different from a uniform distribution, $\mathcal{U}\left[0, x_{i t}\right]$. Column 2 and 3 present similar findings for one-month lag price and the average of four-month lag prices.

The results provide several implications. First, the estimates of $\alpha$ imply that consumers are unlikely to respond to expected marginal price. Second, the estimated shape of the weighing function is consistent with the results in the previous section, and both strategies find that consumers respond to average price rather than marginal or expected marginal 
price. The next section examines the welfare and policy implications of this finding.

\section{$5 \quad$ Welfare Analysis}

\subsection{Nonlinear Pricing and Energy Conservation}

Many electric, natural gas, and water utilities in the US adopted nonlinear pricing similar to California's residential electricity pricing. Policy makers often claim that higher marginal prices for excessive consumption can create an incentive for conservation. Note that the retail price of utility companies is usually regulated and has a zero profit condition with a rate of return. When utility companies switch from a flat marginal rate to multi-tier pricing, they need to lower the marginal price for some tiers to raise the marginal price for other tiers. The effect on aggregate consumption is thus ambiguous because some customers see an increase in price while others see a decrease in price. I use the data in my sample to examine how nonlinear pricing changes consumption compared to a counterfactual flat marginal rate for two scenarios: 1) customers respond to average price and 2) they respond to marginal price.

I calculate counterfactual consumption by making the following assumptions. First, I assume that consumers have a demand function $x_{i}=\lambda_{i} \cdot p_{i}{ }^{\beta}$ with a price elasticity $\beta$ and fixed effects $\lambda_{i}$. Second, based on my empirical findings, I assume that consumers are currently responding to average price. This assumption implies that the observed consumption in the data equals $\lambda_{i} \cdot a p_{i}{ }^{\beta}$. When consumers face a counterfactual flat marginal rate, their counterfactual consumption equals $\lambda_{i} \cdot f l a t^{\beta}$. Finally, I calculate counterfactual consumption $\lambda_{i} \cdot m p_{i}{ }^{\beta}$ by assuming that consumers respond to marginal price with price elasticity $\beta$ when 
they correctly perceive their true marginal price. ${ }^{18}$

When aggregate consumption changes in the counterfactual scenarios, the total revenue and cost also change. To keep total consumption comparable between the observed and two counterfactual cases, I assume that the utility company maintains a profit neutrality condition by adjusting the tariff in the following way. First, I assume that the long-run marginal cost equals the average cost of electricity under the existing nonlinear tariff. For example, for SCE's tariff in 2007, the marginal cost based on this assumption equals $16.73 \notin / \mathrm{kWh} .{ }^{19}$ Then, the alternative flat marginal rate tariff is simply a marginal rate of $16.73 \phi / \mathrm{kWh}$, which produces the same profit as the existing five-tier tariff. Second, I assume that the company adjusts each of the five tier rate by the same proportion to keep the profit neutrality when aggregate consumption changes.

Table 6 presents how nonlinear pricing changes aggregate consumption compared to a counterfactual flat marginal rate. I use the data in SCE in 2007, where consumers had one of the steepest five-tier price schedules. ${ }^{20}$ I include all SCE customers that have the standard five-tier tariff. I compute counterfactual consumption using the medium-long run price elasticity estimate -0.101 . The aggregate consumption increases by $0.28 \%$ if consumers respond to average price. The intuition behind this result is the following. When the price schedule

\footnotetext{
${ }^{18}$ This assumption is plausible if I consider that consumers currently use their average price as an approximation of their true marginal price and the counterfactual consumption is obtained by informing them about the true marginal price. However, there is possibility that their fundamental elasticity can be different for marginal price, which cannot be tested in my data.

${ }^{19}$ The marginal costs based on this assumption can be either lower or higher than the true long-run marginal cost. It can be too low if, for example, the expansion of electricity supply is more costly due to constraints on new transmission lines. It can be too high if, for instance, there are economies of scale in electricity supply. However, for small elasticities, adjustments of alternative tariffs are not very sensitive to the assumption of marginal costs, because the marginal cost affects only the net change in consumption. On the other hand, the calculation of the deadweight is sensitive to assumptions on marginal costs, which I show in the next section.

${ }^{20}$ For other years, and also for San Diego Gas \& Electric, I calculate the same statistics, and the results are similar to the case for SCE in 2007.
} 
is switched from a flat marginal rate to nonlinear pricing, lower electricity users increase their consumption because they face lower price. Higher electricity users decrease consumption but only slightly because their average price does not increase much. In contrast, the marginal price increases substantially. This is why the aggregate consumption decreases by $2.71 \%$ if consumers respond to marginal price. The results suggest that the nonlinear pricing would be effective in reducing aggregate consumption if consumers respond to marginal price. However, if consumers respond to average price, it does not reduce aggregate consumption compared with the counterfactual flat marginal rate pricing.

\subsection{Efficiency Costs of Nonlinear Pricing}

Multi-tier electricity pricing creates efficiency costs because it does not reflect the marginal cost of electricity (Faruqui 2008). ${ }^{21}$ The marginal cost of electricity generally depends on the timing of consumption. However, there is no evidence that the marginal cost depends on the level of a customer's monthly consumption. Among time-invariant electricity pricing, the most efficient pricing is therefore likely to be the flat marginal rate that equals the marginal cost of electricity. ${ }^{22}$ In multi-tier pricing, the marginal prices for lower tiers are too low and those for higher tiers are too high compared to the efficient flat marginal rate. The deadweight loss of price schedule $p(x)$ for a consumer whose consumption equals $x^{*}$ can be calculated by the integral between the efficient price and the price schedule, $d w l(p(x))=\int_{0}^{x^{*}}|p(x)-m c| d x$.

I again start with the assumption that the long-run marginal cost of electricity equals the average cost of electricity under the existing five-tier tariff, $16.73 థ / \mathrm{kWh}$ for SCE in

\footnotetext{
${ }^{21}$ See Borenstein (2012) for the redistribution effect of nonlinear electricity pricing.

${ }^{22}$ Time-variant electricity pricing generally improves efficiency substantially. Such pricing is not applicable for customers in my sample because their meters are read monthly.
} 
2007. This marginal cost can be higher or lower than the social marginal cost depending on the assumptions on environmental externalities from power generation. I thus calculate the deadweight loss for a wide range of the possible social marginal cost of electricity.

Figure 8 shows the aggregate deadweight loss for various values of the social marginal cost of electricity with the price elasticity of -0.101 . For the social marginal cost less than $21.13 థ / \mathrm{kWh}, d w l(m p)$ is larger than $d w l(a p)$. This is because when consumers respond to marginal price, they consume too less on average compared to the efficient level of consumption. However, when the social marginal cost exceeds this value because of large environmental externalities from electricity generation for example, $d w l(a p)$ is larger than $d w l(m p)$. This is because the optimal consumption level in the presence of the negative externalities becomes closer to the quantity obtained with the marginal price response. The welfare impact of the sub-optimizing behavior in the case of electricity consumption thus depends on the social marginal cost of electricity. This result is contrast to the welfare implication for the labor supply response to a nonlinear income tax schedule (Liebman and Zeckhauser, 2004), where the sub-optimal response always produces smaller deadweight loss because workers are less discouraged to work when they misperceive their average tax rate as the true rate.

\section{Conclusion and Discussion}

This paper exploits price variation at spatial discontinuities in California electricity service areas to examine whether consumers respond to marginal price or alternative forms of price in response to nonlinear pricing. The evidence strongly suggests that consumers respond to average price and do not respond to marginal or expected marginal price. I show that this sub-optimizing behavior makes nonlinear pricing unsuccessful in achieving its policy goal of 
energy conservation and substantially changes the efficiency cost of nonlinear pricing.

Why do consumers respond to average price rather than marginal price? Given the information available to most residential electricity customers in my sample period, the information cost of understanding the marginal price of electricity is likely to be substantial. First, monthly utility bills are often complex and make it harder for consumers to understand the nonlinear structure of their pricing. Second, it is difficult for most consumers to monitor cumulative electricity consumption during a billing month without having an in-home display that provides the information about their consumption. In contrast, such information is not required to respond to average price. Consumers can simply use the total payment and consumption on their monthly bill and do not have to understand the actual shape of their price schedule. It can be therefore rational for most consumers to use average price as an approximation of their true marginal price.

The discussion about the information cost lead to an important question for future research: Does information provision help consumers respond to their true marginal price? For income tax schedules, Chetty and Saez (2009) conduct a randomized controlled trial, in which a half of the taxpayers in their sample receive instructions about income tax schedules. They find that the information provision indeed changes the labor supply response to the income tax rate. Similarly, Wolak (2011) and Jessoe and Rapson (2012) find that information provision significantly changes the price elasticity in residential electricity demand. Recent development of information technology in energy markets especially have the potential for providing consumers better information and improve the efficiency of the markets.

\section{References}

Amemiya, T. 1983. "Nonlinear regression models." Handbook of econometrics 1:333-389. 
Aron-Dine, Aviva, Liran Einav, Amy Finkelstein, and Mark R. Cullen. 2012. "Moral Hazard in Health Insurance: How Important Is Forward Looking Behavior?" Working Paper 17802, National Bureau of Economic Research.

Atkinson, A. B and J. E Stiglitz. 1976. "The design of tax structure: direct versus indirect taxation." Journal of Public Economics 6 (1-2):55-75.

BC Hydro. 2008. "2008 Residential Inclining Block Rate Application.”

Black, Sandra E. 1999. "Do Better Schools Matter? Parental Valuation of Elementary Education." Quarterly Journal of Economics 114 (2):577-599.

Blomquist, S. and H. Selin. 2010. "Hourly wage rate and taxable labor income responsiveness to changes in marginal tax rates." Journal of Public Economics 94 (11):878-889.

Blundell, R., A. Duncan, and C. Meghir. 1998. "Estimating labor supply responses using tax reforms." Econometrica 66 (4):827-861.

Borenstein, S., J. B Bushnell, and F. A Wolak. 2002. "Measuring Market Inefficiencies in Californias Restructured Wholesale Electricity Market." The American Economic Review 92 (5):1376-1405.

Borenstein, Severin. 2009. "To What Electricity Price Do Consumers Respond? Residential Demand Elasticity Under Increasing-Block Pricing."

—. 2012. "The Redistributional Impact of Nonlinear Electricity Pricing." American Economic Journal: Economic Policy 4 (3):56-90.

Brown, F. L, L. Hoffman, and J. D Baxter. 1975. "New Way to Measure Price Elasticity." Electrical World 184:52-54.

Brown, J., T. Hossain, and J. Morgan. 2010. "Shrouded Attributes and Information Suppression: Evidence from the Field*." Quarterly Journal of Economics 125 (2):859-876.

Burtraw, Dallas. 2009. "Hearing on Climate Change Legislation: Allowance and Revenue Distribution." US Senate Committee on Finance.

Burtraw, Dallas, Margaret Walls, and Joshua A. Blonz. 2010. "Distributional Impacts of Carbon Pricing Policies in the Electricity Sector." U.S. Energy Taxes, Gilbert E.Metcalf eds. American Tax Policy Institute .

Bushnell, James B. and Erin T. Mansur. 2005. "Consumption under Noisy Price Signals: A Study of Electricity Retail Rate Deregulation in San Diego." Journal of Industrial Economics 53 (4):493-513.

Busse, M., J. Silva-Risso, and F. Zettelmeyer. 2006. "1,000 Cash Back: The Pass-Through of Auto Manufacturer Promotions." The American Economic Review 96 (4):1253-1270.

Carter, D. W and J. W Milon. 2005. "Price knowledge in household demand for utility services." Land Economics 81 (2):265. 
Chetty, R., A. Looney, and K. Kroft. 2009. "Salience and taxation: Theory and evidence." The American Economic Review 99 (4):1145-1177.

Chetty, Raj. 2012. "Bounds on Elasticities With Optimization Frictions: A Synthesis of Micro and Macro Evidence on Labor Supply." Econometrica 80 (3):969-1018.

Chetty, Raj, John N. Friedman, Tore Olsen, and Luigi Pistaferri. 2011. "Adjustment Costs, Firm Responses, and Micro vs. Macro Labor Supply Elasticities: Evidence from Danish Tax Records." The Quarterly Journal of Economics 126 (2):749-804.

Chetty, Raj and Emmanuel Saez. 2009. "Teaching the Tax Code: Earnings Responses to an Experiment with EITC Recipients." National Bureau of Economic Research Working Paper Series No. 14836.

Congress, U. S. 2009. "The American Clean Energy and Security Act of 2009 (HR 2454)." US House of Representative, Washington, DC .

Crawford, Kathleen. 1991. Reflections : a history of the San Diego Gas $\&$ Electric Company 1881-1991. San Diego CA: San Diego Historical Society.

Davidson, Russell and James G. MacKinnon. 1993. "Estimation and Inference in Econometrics." OUP catalogue, Oxford University Press.

de Bartolome, Charles A. M. 1995. "Which tax rate do people use: Average or marginal?" Journal of Public Economics 56 (1):79-96.

DellaVigna, S. 2009. "Psychology and economics: Evidence from the field." Journal of Economic Literature 47 (2):315-372.

Diamond, Peter A. 1998. "Optimal Income Taxation: An Example with a U-Shaped Pattern of Optimal Marginal Tax Rates." The American Economic Review 88 (1):83-95.

Faruqui, Ahmad. 2008. "Inclining Toward Efficiency." Public Utilities Fortnightly (August).

Feldman, Naomi E. and Peter Katuscak. 2006. "Should the Average Tax Rate Be Marginalized?" CERGE-EI Working Paper wp304, The Center for Economic Research and Graduate Education - Economic Institute, Prague.

Finkelstein, Amy. 2009. "E-ZTAX: Tax Salience and Tax Rates." The Quarterly Journal of Economics 124 (3):969-1010.

Fujii, Edwin T. and Clifford B. Hawley. 1988. "On the Accuracy of Tax Perceptions." The Review of Economics and Statistics 70 (2):344-347.

Gabaix, Xavier. 2011. "A Sparsity-Based Model of Bounded Rationality." NBER Working Paper 16911, National Bureau of Economic Research, Inc.

Gabaix, Xavier and David Laibson. 2006. "Shrouded Attributes, Consumer Myopia, and Information Suppression in Competitive Markets." The Quarterly Journal of Economics 121 (2):505-540. 
Goolsbee, Austan. 2000. "It's not about the money: Why natural experiments don't work on the rich." The Economic Consequences of Taxing the Rich, J. Slemrod, ed. Russell Sage Foundation and Harvard University Press: Cambridge, MA .

Hausman, J. A. 1985. "The econometrics of nonlinear budget sets." Econometrica $53(6): 1255-1282$.

Heckman, James. 1983. "Comment on Stochastic Problems in the Simulation of Labor Supply." In M. Feldstein, ed., Behavioral Simulations in Tax Policy Analysis. University of Chicago Press, 70-82.

. 1996. "A Comment on Eissa." Empirical foundations of household taxation, $M$. Feldstein and J. Poterba, eds. University of Chicago, Chicago, Illinois. .

Hossain, T. and J. Morgan. 2006. “... plus shipping and handling: Revenue (non) equivalence in field experiments on ebay." The BE Journal of Economic Analysis 65 Policy 6 (2):3.

Huang, Ching-I. 2008. "Estimating demand for cellular phone service under nonlinear pricing." Quantitative Marketing and Economics 6 (4):371-413.

Jessoe, Katrina and David Rapson. 2012. "Knowledge is (Less) Power: Experimental Evidence from Residential Energy Use." Working Paper 18344, National Bureau of Economic Research.

Joskow, P. L. 2001. "California's electricity crisis." Oxford Review of Economic Policy $17(3): 365$.

Lee, David S. and Thomas Lemieux. 2010. "Regression Discontinuity Designs in Economics." Journal of Economic Literature 48 (2):281-355.

Liebman, Jeffrey. 1998. "The impact of the earned income tax credit on incentives and income distribution." Tax policy and the economy :83-119.

Liebman, Jeffrey and Richard Zeckhauser. 2004. "Schmeduling."

Malmendier, U. and Y. H. Lee. 2011. "The bidder's curse." The American Economic Review $101(2): 749-787$.

Mirrlees, J. A. 1971. "An exploration into the theory of optimum income taxation." Review of Economic Studies 38 (114):175-208.

Moffitt, R. 1990. "The econometrics of kinked budget constraints." The Journal of Economic Perspectives 4 (2):119-139.

Myers, William. 1983. Iron men and copper wires : a centennial history of the Southern California Edison Company. Glendale Calif.: Trans-Anglo Books.

Nieswiadomy, Michael L. and David J. Molina. 1991. "A Note on Price Perception in Water Demand Models." Land Economics 67 (3):352-359. 
Olmstead, S. M, W. Michael Hanemann, and R. N Stavins. 2007. "Water demand under alternative price structures." Journal of Environmental Economics and Management 54 (2):181-198.

Puller, Steven L. 2007. "Pricing and Firm Conduct in California's Deregulated Electricity Market." Review of Economics and Statistics 89 (1):75-87.

Reiss, Peter C. and Matthew W. White. 2005. "Household electricity demand, revisited." Review of Economic Studies 72 (3):853-883.

- 2008. "What changes energy consumption? Prices and public pressures." RAND Journal of Economics 39 (3):636-663.

Saez, E., J. Slemrod, and S. H. Giertz. 2012. "The elasticity of taxable income with respect to marginal tax rates: A critical review." Journal of Economic Literature 50 (1):3-50.

Saez, Emmanuel. 1999. "Do Taxpayers Bunch at Kink Points?" National Bureau of Economic Research Working Paper Series No. 7366.

- 2010. "Do Taxpayers Bunch at Kink Points?" American Economic Journal: Economic Policy 2 (3):180-212.

Shin, Jeong-Shik. 1985. "Perception of Price When Price Information Is Costly: Evidence from Residential Electricity Demand." The Review of Economics and Statistics 67 (4):59198.

Wolak, F. A. 2011. "Do Residential Customers Respond to Hourly Prices? Evidence from a Dynamic Pricing Experiment." The American Economic Review 101 (3):83-87. 
Figure 1: Theoretical Predictions about Consumers' Perceived Price Panel A. Three theoretical predictions

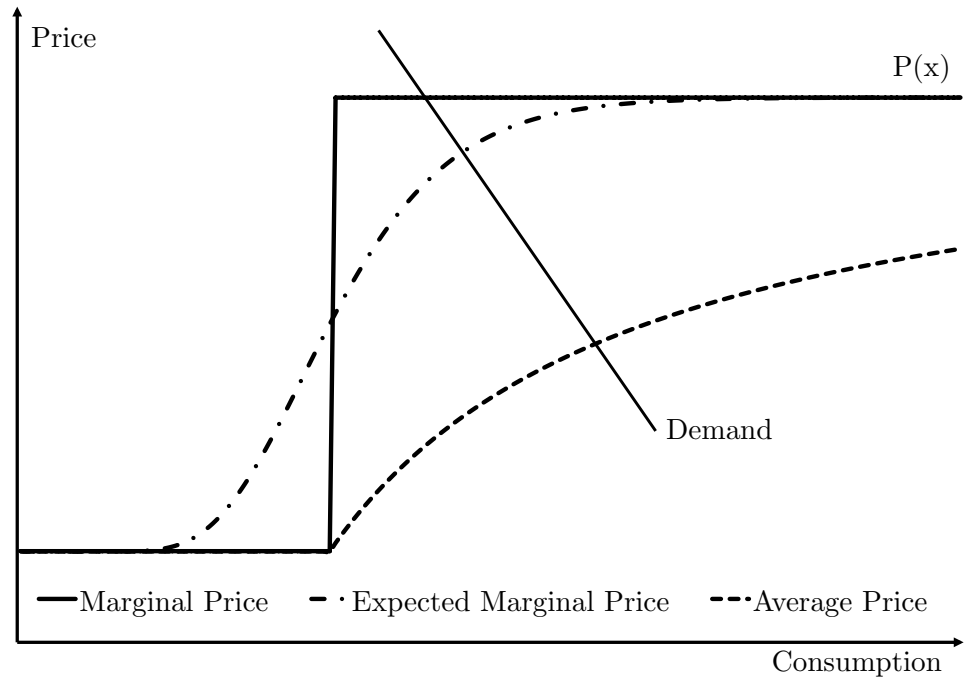

Panel B. The shape of density functions of $w(\epsilon)$ that convert $\tilde{p}(x)$ to the three prices

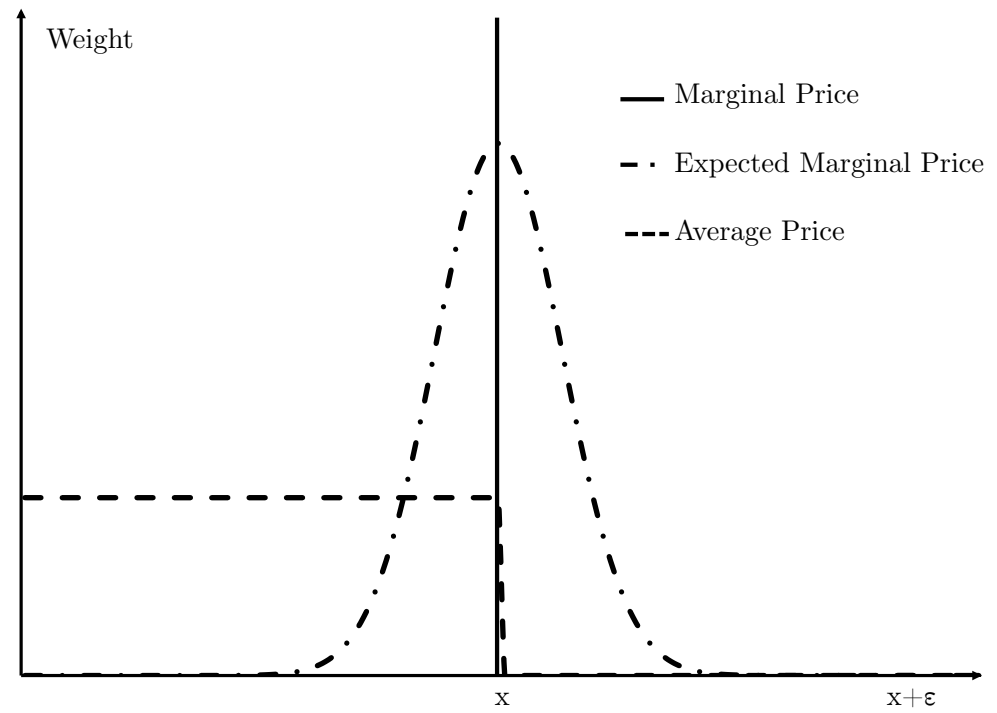

Notes: Panel A uses a simple example of nonlinear price schedules to describe three theoretical predictions about consumers' perceived price. Panel B shows the density functions of $w(\epsilon)$ that convert $\tilde{p}(x)$ to the three corresponding prices presented in Panel (A). 
Figure 2: Border of Electricity Service Areas in Orange County, California

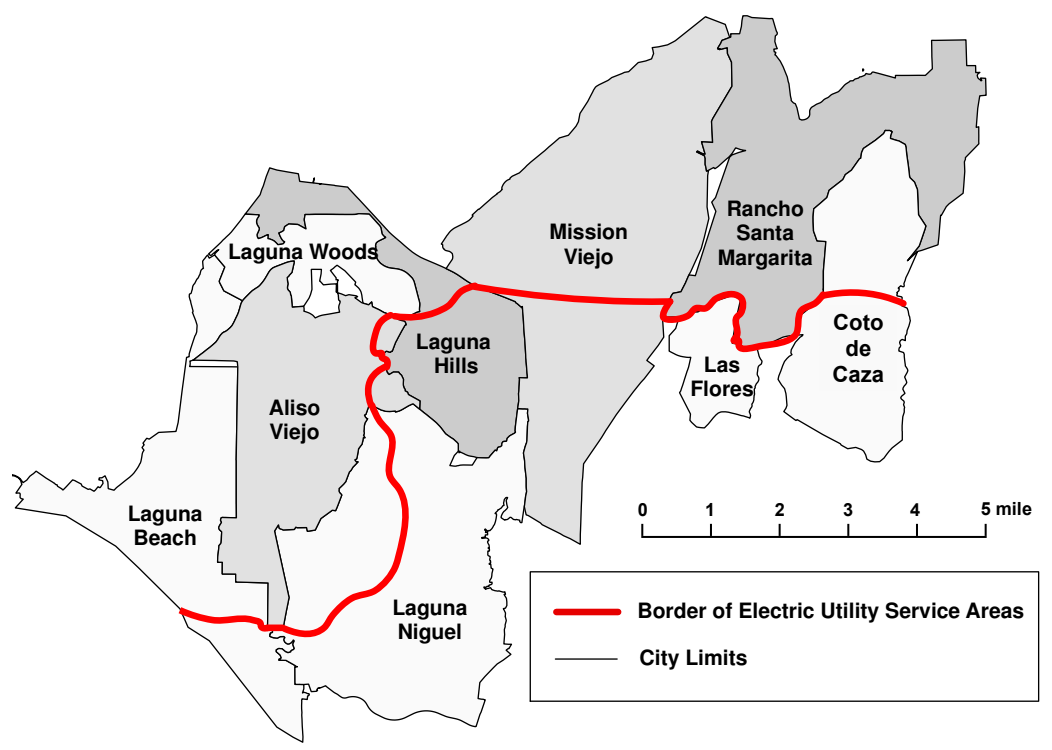

Notes: The border of electricity service areas lies within the city limits in six cities. SCE serves the north side of the border and SDG\&E serves the south side of the border.

Figure 3: An Example of Cross-Sectional Price Variation in Nonlinear Pricing

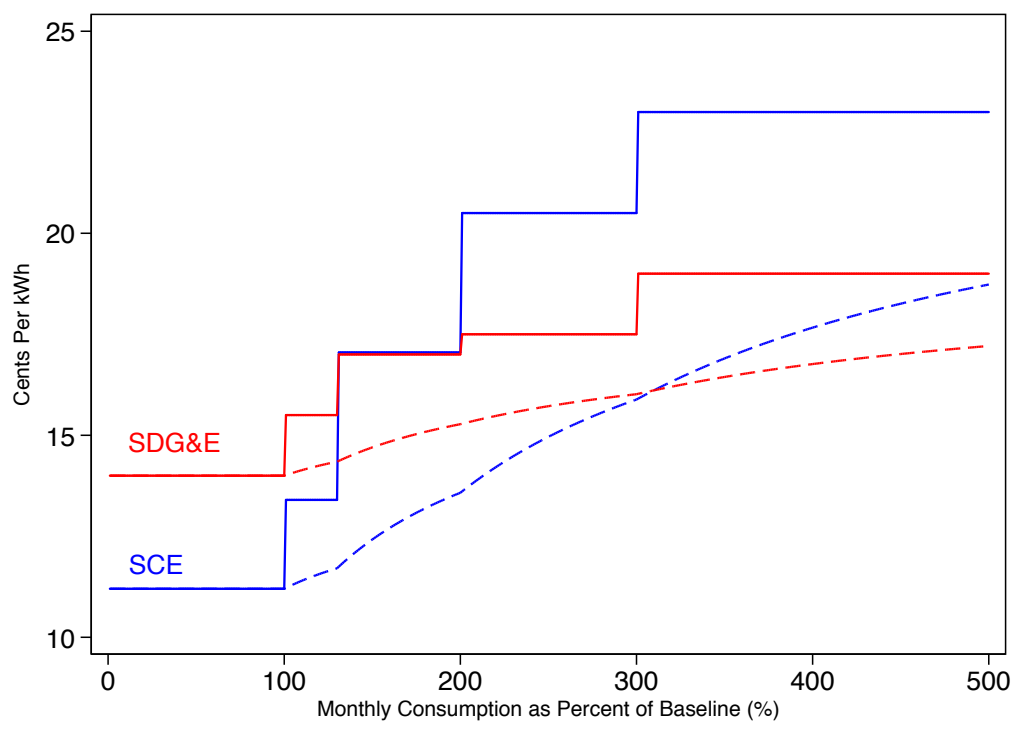

Notes: To show an example of cross-sectional price variation, this figure presents the marginal price (solid) and the average price (dashed) for SCE and SDG\&E in 2002. 
Figure 4: Time-Series Price Variation in Nonlinear Electricity Pricing

Panel A. Southern California Edison (SCE)

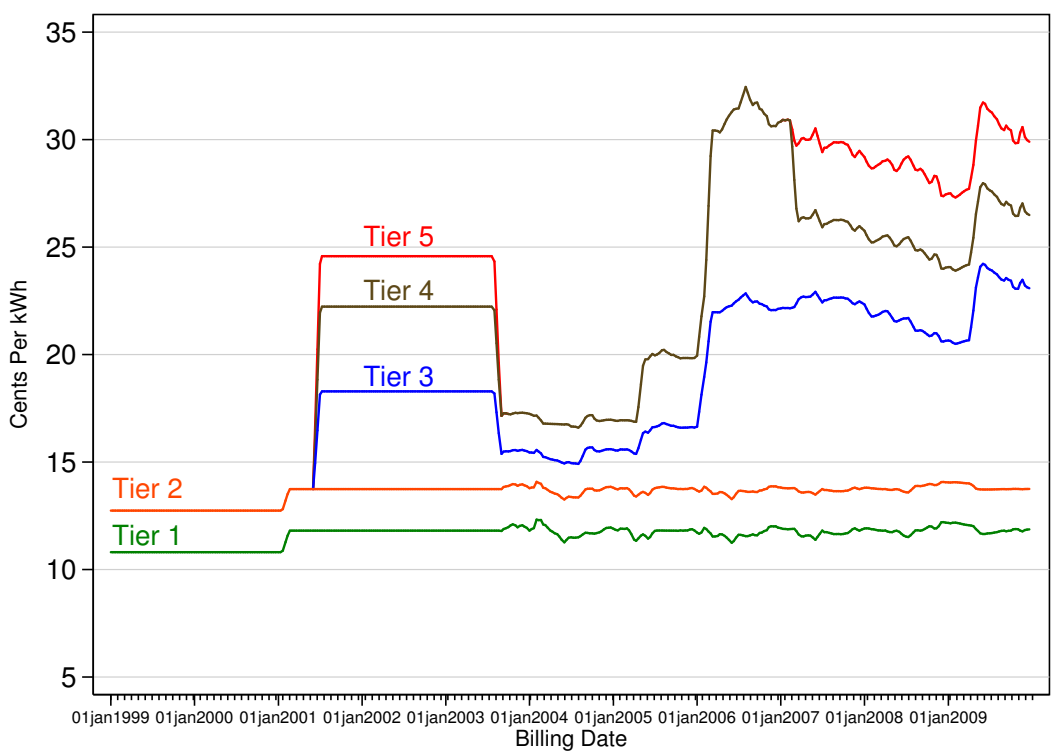

Panel B. San Diego Gas \& Electric (SDG\&E)

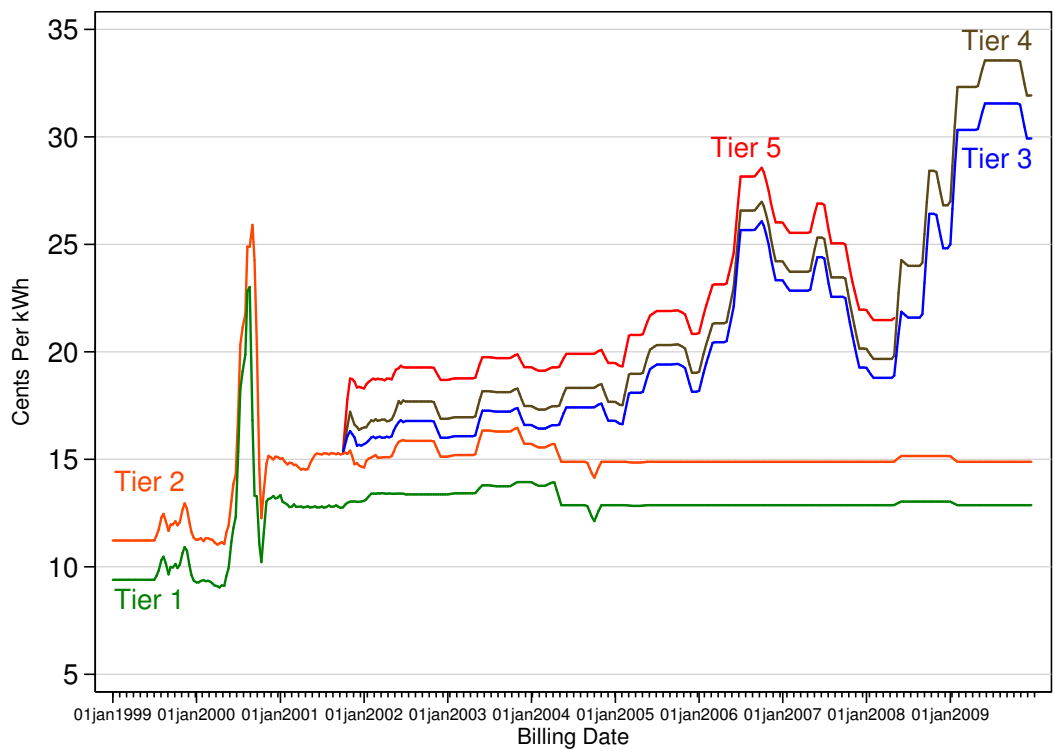

Notes: The figure shows how residential electricity prices changed over time in Southern California Edison and San Diego Gas \& Electric. Each of the five tier rates corresponds to the tier rates in the five-tier increasing block price schedules presented in Figure 3. The third, fourth, and fifth tiers did not exist before 2001. The fifth tier did not exist between 2004 and 2006 in SCE, and after 2008 in SDG\&E. 
Figure 5: Consumption Distributions and Nonlinear Price Schedules

Panel A. 1999

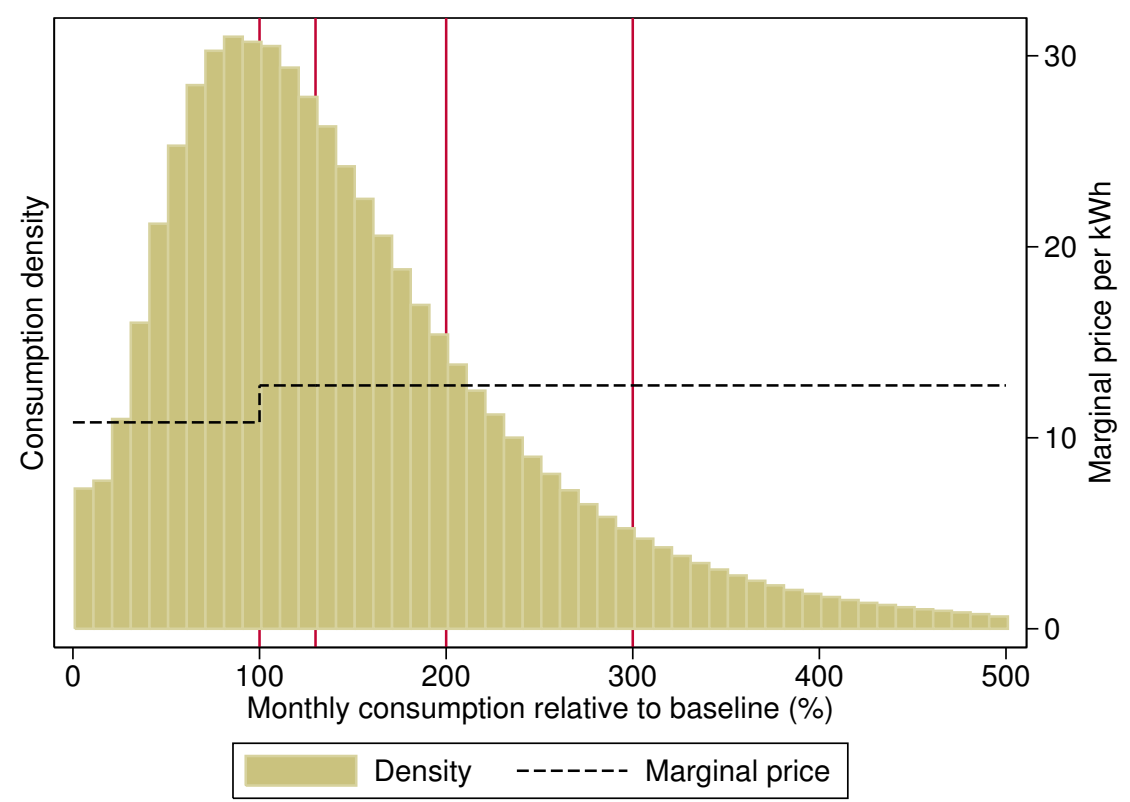

Panel B. 2007

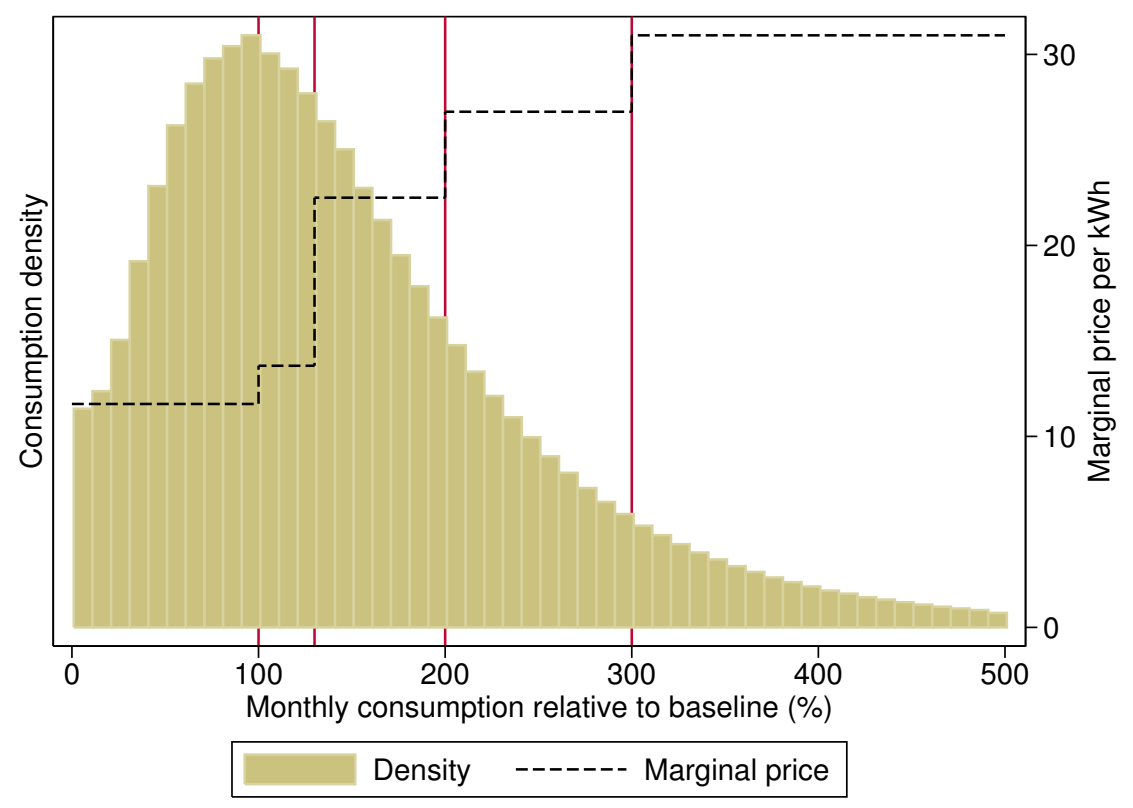

Notes: The figure shows the histogram of household-level monthly electricity consumption for Southern California Edison in 1999 (Panel A) and 2007 (Panel B). The figure also shows the nonlinear price schedule for each year. The vertical solid lines show the kink points of the nonlinear price schedule. 
Figure 6: Difference-in-Differences in Price and Consumption

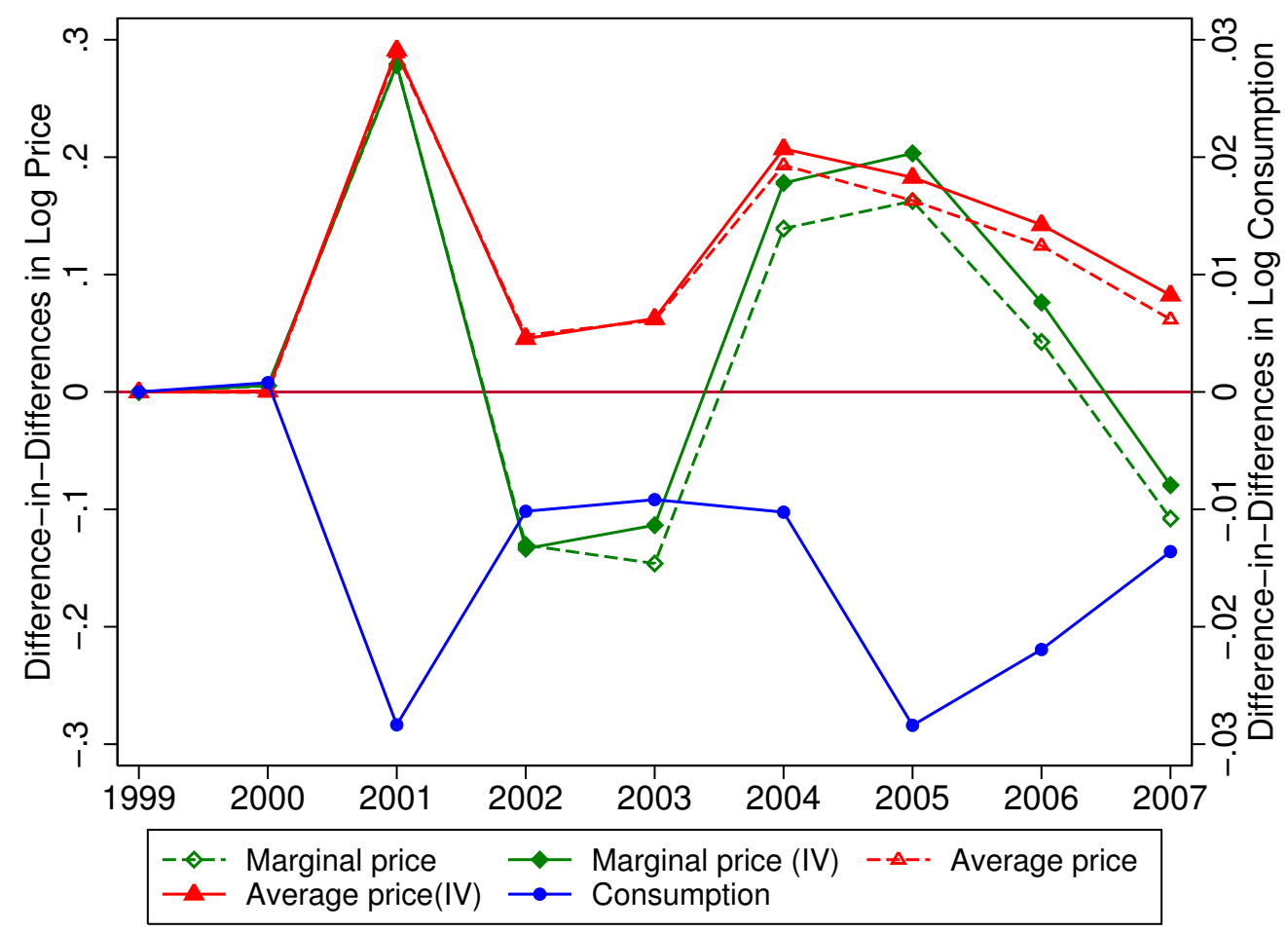

Notes: The figure shows the difference-in-differences in price and consumption of January billing months relative to year 1999 for customers whose consumption is in the forth tier of the five-tier price schedule. For example, the plot of marginal price presents how SDG\&E's log marginal price evolved from 1999 relative to SCE. First, for each side of the border, I calculate the mean log change in price and consumption. Then, I calculate difference-in-differences by subtracting the mean log change of SCE customers from the mean log change of SDG\&E customers. 
Figure 7: Shape of Weighting Functions: Examples and Estimation Results

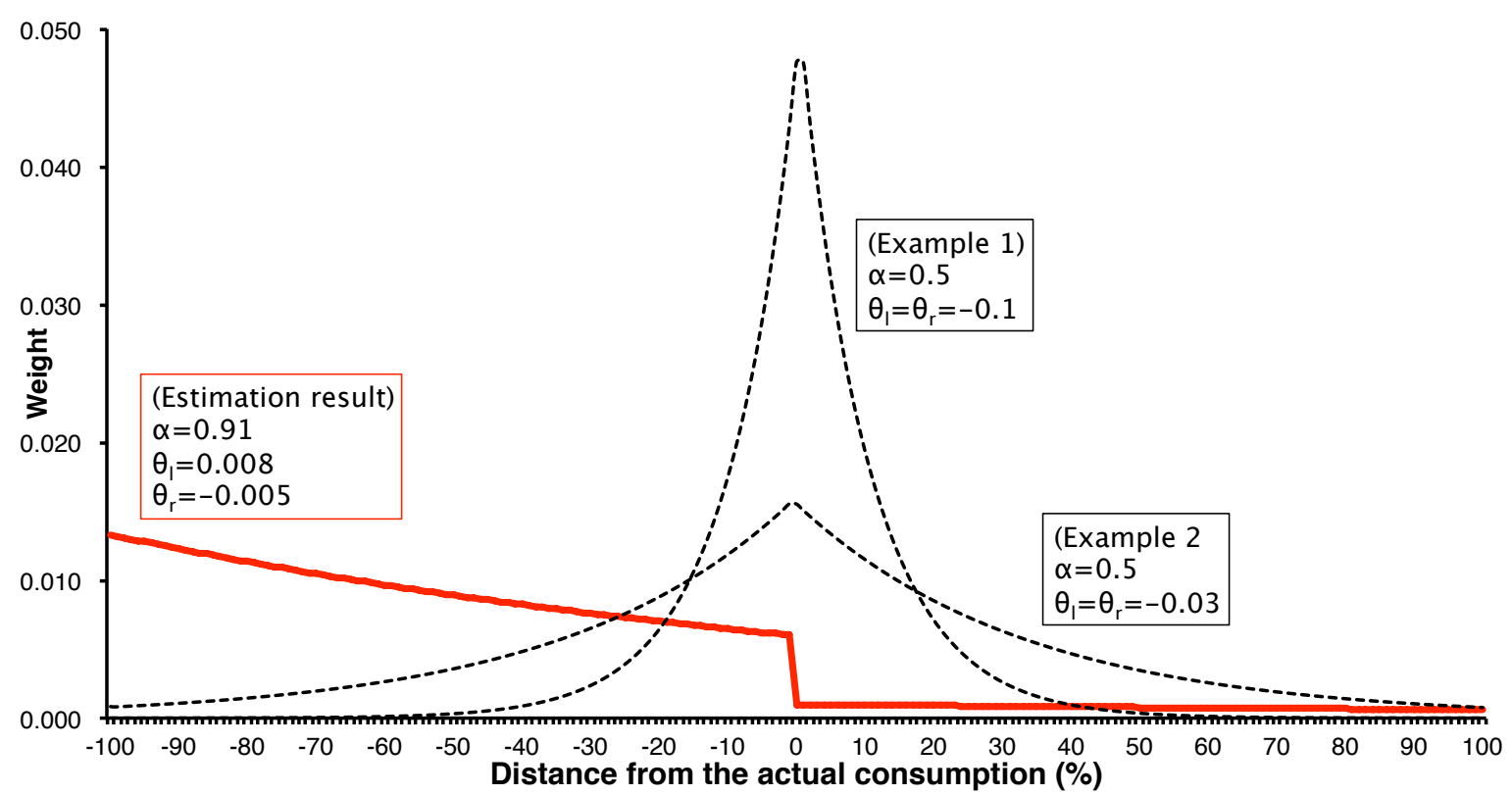

Notes: The dashed lines illustrate two examples of the weighting functions of equation (5). The first example shows the case with $\alpha=0.5$ and $\theta_{l}=\theta_{r}=-0.1$, in which consumers care about the price of the left and right of $x_{i t}$ equally but put larger weights on the price close to $x_{i t}$. The second example shows a similar case but consumers care about the price further away from $x_{i t}$. The solid line shows the estimation result of $w(\alpha, \theta)$ that is shown in Table 5. 
Figure 8: Efficiency Costs of Nonlinear Pricing

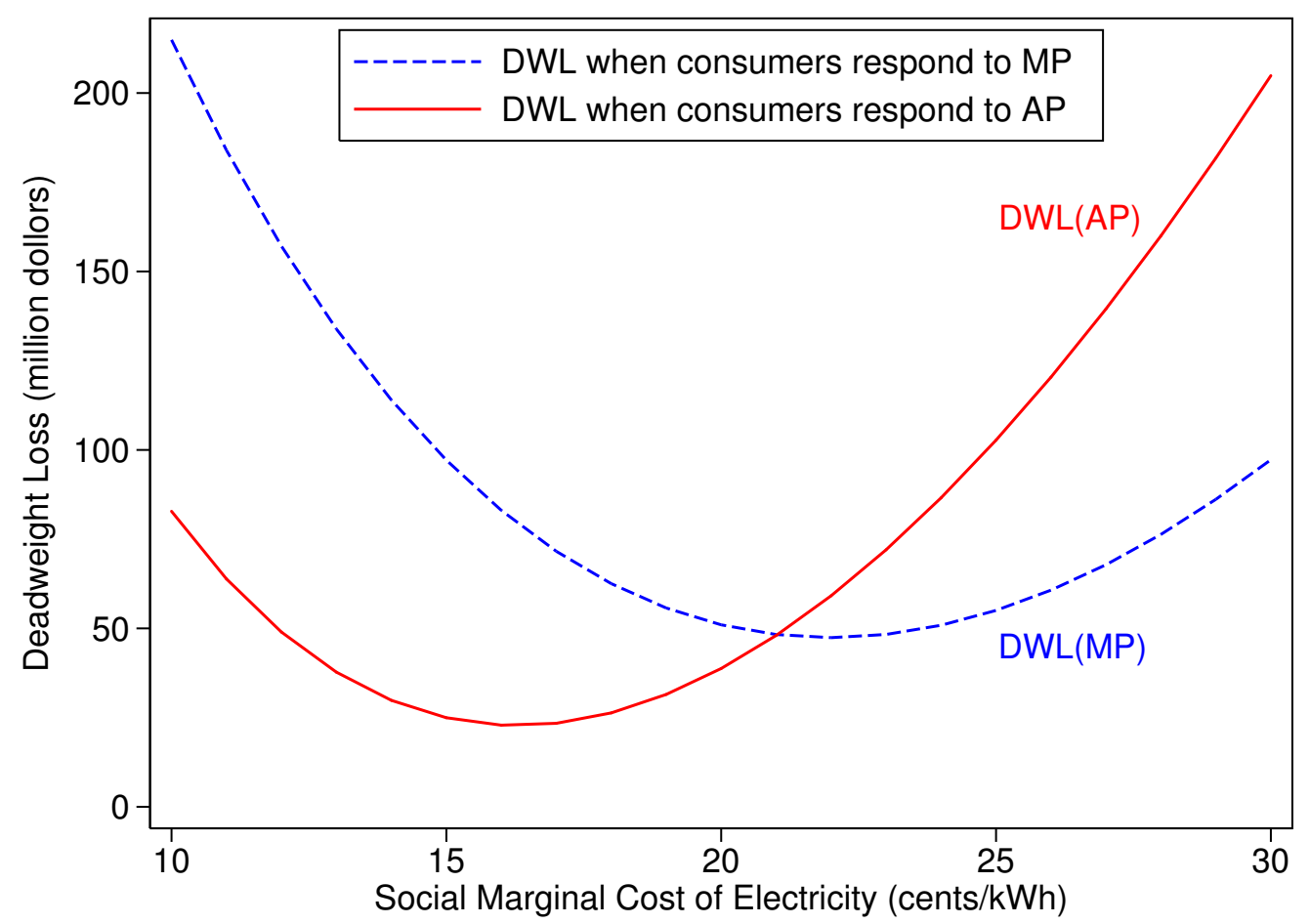

Notes: This figure presents the deadweight loss from the five-tier tariffs in Southern California Edison in 2007 for different assumptions on the social marginal cost of electricity as well as on how consumers respond to nonlinear pricing. The deadweight loss is calculated with the price elasticity of -0.101 . The solid line shows the deadweight loss when consumers respond to their average price. The dashed line displays a counterfactual deadweight loss when consumers respond to their marginal price. The deadweight loss is larger for the marginal price response when the social marginal cost is less than $21.13 \notin / \mathrm{kWh}$ and becomes smaller when the social marginal cost exceeds the cutoff value. 
Table 1: Summary Statistics and Differences in Means

\begin{tabular}{|c|c|c|c|c|c|c|}
\hline \multirow{3}{*}{ Data from Census 2000} & \multicolumn{2}{|c|}{ SCE } & \multicolumn{2}{|c|}{ SDG\&E } & \multicolumn{2}{|c|}{ Difference } \\
\hline & \multicolumn{2}{|c|}{ Mean (S.E) } & \multicolumn{2}{|c|}{ Mean (S.E) } & \multicolumn{2}{|c|}{ Mean (S.E) } \\
\hline & & & & & & \\
\hline Income per capita $(\$)$ & 41121 & $(1655)$ & 40926 & $(1623)$ & -195 & $(2303)$ \\
\hline Median home value $(\$)$ & 398937 & $(20576)$ & 405911 & $(19671)$ & 6974 & $(28275)$ \\
\hline Median rent $(\$)$ & 1,366 & $(42)$ & 1,388 & $(63)$ & 22 & $(75)$ \\
\hline Average household size & 2.71 & $(0.07)$ & 2.82 & $(0.05)$ & 0.10 & $(0.09)$ \\
\hline Median age & 47.40 & $(1.06)$ & 45.75 & $(0.55)$ & -1.64 & $(1.19)$ \\
\hline$\%$ owner occupied housing & 81.44 & $(1.65)$ & 84.48 & $(1.91)$ & 3.05 & $(2.51)$ \\
\hline$\%$ employment of males & 75.39 & $(1.87)$ & 78.71 & $(1.14)$ & 3.31 & $(2.19)$ \\
\hline$\%$ employment of females & 58.26 & $(1.63)$ & 58.51 & $(1.22)$ & 0.24 & $(2.02)$ \\
\hline$\%$ colleage degree & 50.77 & $(1.25)$ & 53.10 & $(1.21)$ & 2.33 & $(1.73)$ \\
\hline$\%$ high school degree & 34.77 & $(1.01)$ & 32.23 & $(0.93)$ & -2.54 & $(1.37)^{*}$ \\
\hline & 4.20 & $(0.28)$ & 4.02 & $(0.32)$ & -0.18 & $(0.43)$ \\
\hline$\%$ white & 85.51 & $(0.86)$ & 83.77 & $(0.95)$ & -1.74 & $(1.28)$ \\
\hline$\%$ hispanics & 9.33 & $(0.57)$ & 9.59 & $(0.72)$ & 0.26 & $(0.91)$ \\
\hline$\%$ asian & 6.94 & $(0.61)$ & 8.27 & $(0.67)$ & 1.32 & $(0.90)$ \\
\hline$\%$ black & 1.19 & $(0.15)$ & 0.86 & $(0.16)$ & -0.33 & $(0.22)$ \\
\hline \multicolumn{7}{|l|}{$\underline{\text { Electricity Billing Data }}$} \\
\hline Electricity use (kWh/day) & 22.96 & $(0.12)$ & 24.00 & $(0.13)$ & 1.04 & $(0.18)^{* * *}$ \\
\hline $\ln ($ Electricity use $)$ & 2.94 & $(0.004)$ & 2.96 & $(0.005)$ & 0.013 & $(0.006)^{*}$ \\
\hline $\ln$ (Electricity use) in 1999 & 2.89 & $(0.004)$ & 2.88 & $(0.005)$ & -0.006 & $(0.007)$ \\
\hline
\end{tabular}

Notes: For each variable, I show the mean and standard error for SCE customers and SDG\&E customers in the six cities that have the territory border of SCE and SDG\&E within the city limits. The last column shows the difference in the mean with the standard error of the difference. I cluster standard errors at the census block group level for the Census data and at the customer level for the electricity billing data. *, **, and ${ }^{* * *}$ show $10 \%, 5 \%$, and $1 \%$ statistical significance. 
Table 2: Encompassing Tests: Marginal Price vs. Average Price

\begin{tabular}{lcccccc}
\hline \hline & $(1)$ & $(2)$ & $(3)$ & $(4)$ & $(5)$ & $(6)$ \\
\hline$\Delta \ln \left(\right.$ Marginal Price $\left._{\mathrm{t}}\right)$ & -0.040 & & 0.005 & & & \\
& $(0.004)$ & & $(0.011)$ & & & \\
$\Delta \ln \left(\right.$ Average Price $\left._{\mathrm{t}}\right)$ & & -0.055 & -0.061 & & & \\
& & $(0.005)$ & $(0.014)$ & & & \\
$\Delta \ln \left(\right.$ Marginal Price $\left._{\mathrm{t}-1}\right)$ & & & & -0.052 & & 0.003 \\
& & & & $(0.004)$ & & $(0.012)$ \\
$\Delta \ln \left(\right.$ Average Price $\left._{\mathrm{t}-1}\right)$ & & & & & -0.075 & -0.079 \\
& & & & & $(0.005)$ & $(0.014)$ \\
\hline
\end{tabular}

Notes: This table shows the results of the IV regression in equation (3) with fixed effects and control variables specified in the equation. The unit of observation is household-level monthly electricity bill. The dependent variable is the log change in electricity consumption in billing period $t$ from billing period $t-12$. The sample period is from January 1999 to December 2007 and the sample size is 3,712,704 for columns 1 to 3 and $3,674,030$ for columns 4 to 6 . Standard errors in parentheses are clustered at the household level to adjust for serial correlation.

Table 3: Lagged Responses and Medium-Long Run Price Elasticity

\begin{tabular}{|c|c|c|c|c|c|}
\hline & & \multicolumn{4}{|c|}{ "Medium-Long Run Reponses } \\
\hline & & 1 month & \multirow{2}{*}{$\frac{2 \text { month }}{(3)}$} & \multirow{2}{*}{$\frac{3 \text { month }}{(4)}$} & \multirow{2}{*}{$\frac{4 \text { montl }}{(5)}$} \\
\hline & (1) & $(2)$ & & & \\
\hline \multirow[t]{2}{*}{$\Delta \ln \left(\right.$ Average Price $\left._{t}\right)$} & 0.002 & & & & \\
\hline & $(0.006)$ & & & & \\
\hline \multirow[t]{2}{*}{$\Delta \ln \left(\right.$ Average Price $\left.e_{t-1}\right)$} & -0.045 & & & & \\
\hline & $(0.008)$ & & & & \\
\hline \multirow[t]{2}{*}{$\Delta \ln \left(\right.$ Average Price $\left.\mathrm{t}_{\mathrm{t}-2}\right)$} & -0.036 & & & & \\
\hline & $(0.007)$ & & & & \\
\hline \multirow[t]{2}{*}{$\Delta \ln \left(\right.$ Average Price $\left._{t-3}\right)$} & -0.013 & & & & \\
\hline & $(0.006)$ & & & & \\
\hline$\Delta \ln ($ Average of Lag & & -0.075 & -0.093 & -0.099 & -0.101 \\
\hline Average Prices) & & $(0.005)$ & $(0.005)$ & $(0.005)$ & $(0.005)$ \\
\hline
\end{tabular}

Notes: See notes in Table 3. The dependent variable is the log change in electricity consumption in billing period $t$ from billing period $t-12$. Because the four-month lag price is unknown for the first four months of the sample period, I include monthly bills from May 1999 to December 2007 and the sample size is 3,558,008. Standard errors in parentheses are clustered at the household level to adjust for serial correlation. 
Table 4: Encompassing Tests: Expected Marginal Price vs. Average Price

\begin{tabular}{lcccc}
\hline \hline & $(1)$ & $(2)$ & $(3)$ & $(4)$ \\
\hline$\Delta \ln \left(\right.$ Expected Marginal Price $\left._{\mathrm{t}}\right)$ & -0.043 & -0.009 & & \\
& $(0.004)$ & $(0.011)$ & & \\
$\Delta \ln \left(\right.$ Average Price $\left._{\mathrm{t}}\right)$ & & -0.057 & & \\
& & $(0.014)$ & & \\
$\Delta \ln \left(\right.$ Expected Marginal Price $\left._{\mathrm{t}-1}\right)$ & & -0.055 & 0.005 \\
& & & $(0.004)$ & $(0.011)$ \\
$\Delta \ln \left(\right.$ Average Price $\left._{\mathrm{t}-1}\right)$ & & & -0.083 \\
& & & $(0.014)$ \\
\hline
\end{tabular}

Notes: See notes in Table 3. This table shows the results of the IV regression in equation (3) but include expected marginal price instead of marginal price. The dependent variable is the log change in electricity consumption in billing period $t$ from billing period $t-12$. The data include monthly bills from January 1999 to December 2007 and the sample size is 3,712,704 for columns 1 to 2 and 3,674,030 for columns 3 to 4. Standard errors in parentheses are clustered at the household level to adjust for serial correlation.

Table 5: Estimation of the Shape of Perceived Price

\begin{tabular}{lccc}
\hline \hline & \multicolumn{3}{c}{ Price Variable } \\
\cline { 2 - 4 } & $\begin{array}{c}\text { Current month } \\
(1)\end{array}$ & $\begin{array}{c}\text { One-month lag } \\
(2)\end{array}$ & $\begin{array}{c}\text { Four-month average } \\
(3)\end{array}$ \\
\hline Weighting parameter $\alpha$ & 0.911 & 0.896 & 0.883 \\
& $(0.082)$ & $(0.083)$ & $(0.087)$ \\
Slope parameter $\theta_{l}$ & 0.008 & 0.013 & 0.015 \\
Slope parameter $\theta_{r}$ & $(0.008)$ & $(0.009)$ & $(0.010)$ \\
& -0.005 & -0.009 & 0.001 \\
Elasticity parameter $\beta$ & $(0.015)$ & $(0.015)$ & $(0.017)$ \\
& -0.059 & -0.086 & -0.114 \\
p-value for $\mathrm{H}_{0}: \alpha=0.5$ & $(0.005)$ & $(0.006)$ & $(0.006)$ \\
p-value for $\mathrm{H}_{0}: \alpha=1$ & 0.00 & 0.00 & 0.00 \\
\end{tabular}

Notes: See notes in Table 3. This table shows the results of the nonlinear IV regression in equation (5). Standard errors in parentheses are clustered at the household level to adjust for serial correlation. Column 1 uses the contemporaneous price, column 2 uses the one-month lagged price, and column 3 uses the average of one, two, three, and four-month lagged prices as a price variable in the regression. 
Table 6: The Effect of Nonlinear Pricing on Energy Conservation

\begin{tabular}{lcc}
\hline \hline & \multicolumn{2}{c}{ Assumption on Consumers' Perceived Price } \\
\cline { 2 - 3 } & Average Pirce & Marginal Price \\
\hline (A) Consumption under & 20,611 & 19,995 \\
Five-tier Nonlinear Pricing & & \\
& & 20,553 \\
(B) Consumption under & 20,553 & \\
Counterfactual Flat Rate & & $-2.71 \%$ \\
\% Change from (B) to (A) & $0.28 \%$ & $(0.43 \%)$ \\
\hline
\end{tabular}

Notes: The table shows how nonlinear pricing changes aggregate consumption compared to a counterfactual flat marginal rate for two scenarios: 1) customers respond to average price and 2) customers respond to marginal price. This table uses the data in SCE in 2007, where consumers had one of the steepest five-tier price schedules. Note that the main results do not change when I use the data in other years or in SDG\&E. Asymptotic standard errors are calculated by the delta method based on the standard errors of the estimated price elasticity. 


\section{Appendix}

Figure A.1: Service Territories of California's Investor-Owned Electric Utilities

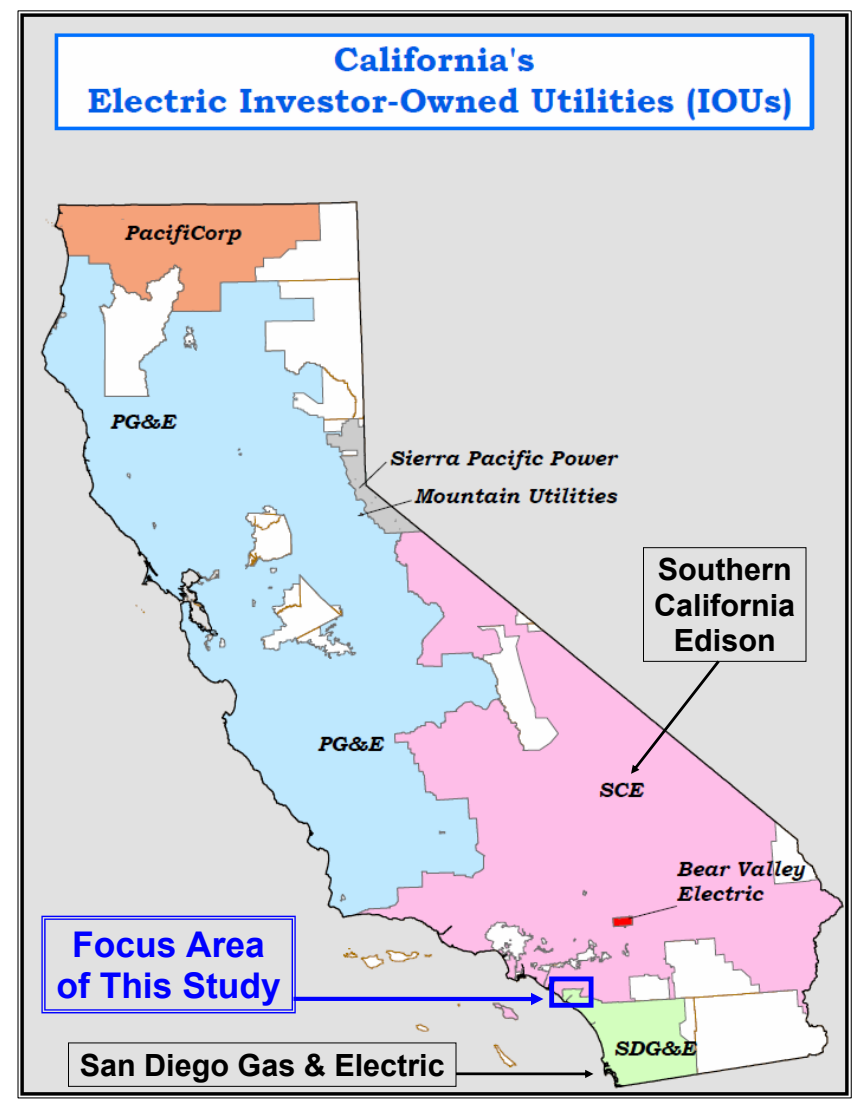

Notes: This figure shows a service territory map of California's investor-owned electric utilities. The original map is provided by the California Energy Commission. Blank areas indicate that these areas are served by electric utilities that are not investor-owned. In this study, I use two electric utilities: Southern California Edison (SCE) and San Diego Gas \& Electric (SDG\&E). SCE provides electricity for a large part of southern California, whereas SDG\&E covers a major part of San Diego County and the southern part of Orange County. This study particularly focuses on the territory border of SCE and SDG\&E in Orange County, which is shown in Figure 2. 
Figure A.2: Changes in Consumption from 1999 to 2000 by Distance from the Utility Border

Panel A. Changes in Consumption from July 1999 to July 2000

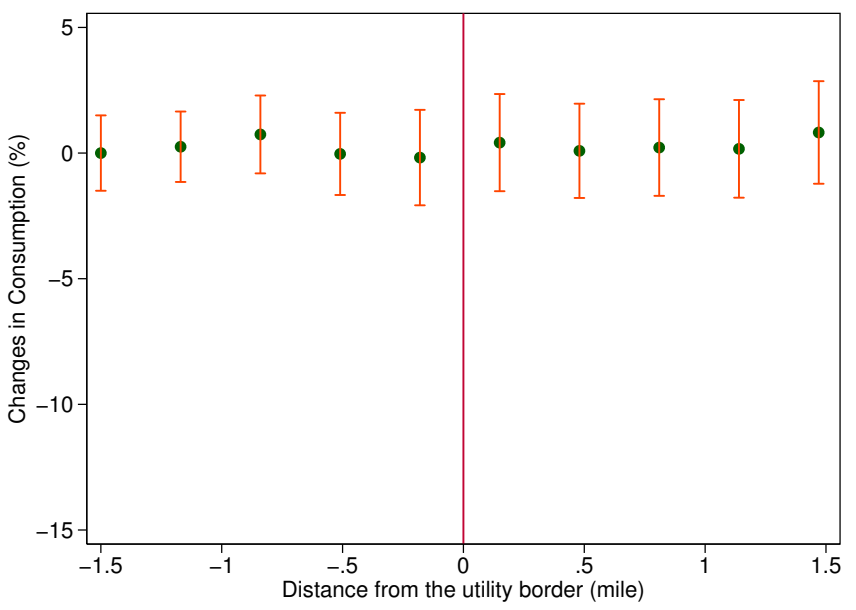

Panel B. Changes in Consumption from August 1999 to August 2000

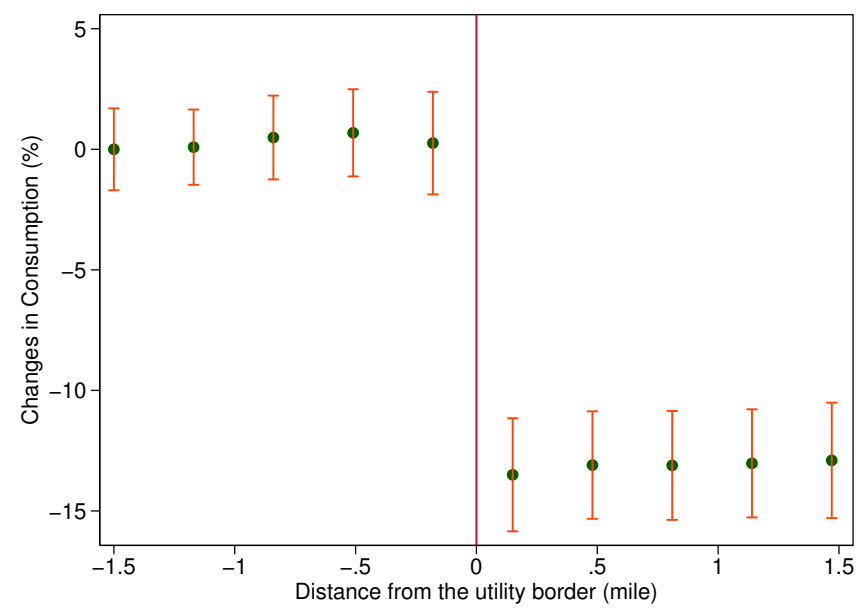

Notes: The figure provides evidence of the validity of the spatial regression discontinuity design and suggests that using samples further close to the utility border does not affect my estimation results, which I show in Table A.1. The horizontal axis shows miles from the border using negative values for SCE territory and positive values for SDG\&E territory. The left hand side of the vertical line represents the distance from the border for SCE customers and the right hand side represents the distance from the border for SDG\&E customers. The dots show the mean percent change in consumption from a billing month in 1999 to the same billing month in 2000 in a 0.25 mile bandwidth. City-by-time fixed effects and billing-cycle-by-time fixed effects are subtracted to control for weather and other factors. The range bar shows the $95 \%$ confidence intervals. Consumption between SCE and SDG\&E customers are not systematically different before the utility companies had different price changes in the summer of 2000 , and it is systematically different after the price change. 
Table A.1: Robustness Checks

\begin{tabular}{cccccc}
\hline \hline & Main Result & $\begin{array}{c}\text { Unbalanced } \\
\text { Panel }\end{array}$ & $\begin{array}{c}\text { IV based on } \\
\text { consumption }\end{array}$ & $\begin{array}{c}\text { Samples in } \\
2 \text { miles from }\end{array}$ & $\begin{array}{c}\text { Samples in } \\
1 \text { mile from } \\
\text { in 1999 }\end{array}$ \\
\cline { 2 - 6 } & $(1)$ & $(2)$ & $(3)$ & $(4)$ & $(5)$ \\
\hline$\Delta \ln \left(\right.$ Marginal Price $\left._{\mathrm{t}-1}\right)$ & 0.003 & 0.006 & -0.003 & 0.013 & 0.009 \\
& $(0.012)$ & $(0.009)$ & $(0.015)$ & $(0.013)$ & $(0.019)$ \\
$\Delta \ln \left(\right.$ Average Price $\left._{\mathrm{t}-1}\right)$ & -0.079 & -0.084 & -0.074 & -0.082 & -0.084 \\
& $(0.014)$ & $(0.012)$ & $(0.020)$ & $(0.017)$ & $(0.025)$ \\
\hline $\mathrm{N}$ & $3,674,030$ & $6,876,201$ & $3,674,030$ & $2,706,455$ & $1,367,050$ \\
\hline
\end{tabular}

Notes: This table shows the results of the IV regression in equation (3) with fixed effects and control variables specified in the equation for different samples and alternative instruments. See notes in Table 3. Column 1 shows the main result that is presented in Table 3. Column 2 uses unbalanced panel data that include all households who open and close their electricity account during my sample period, from January 1999 to December 2007. Column 3 uses alternative instrument. I calculate the mean consumption in 1999 for each customer. Then, I calculate the policy-induced price change by using this value. Column 4 and 5 limit my sample to households within a certain distance from the territory border of SCE and SDG\&E. Standard errors in parentheses are clustered at the household level to adjust for serial correlation. 